\title{
THE WUWEI MEDICAL MANUSCRIPTS: A BRIEF INTRODUCTION AND TRANSLATION
}

\author{
Yong Yang and Miranda Brown*
}

\begin{abstract}
Discovered by farmers from an unmarked tomb in 1972 in Gansu, the Wuwei strips and tablets set forth a wealth of information about ancient Chinese drug formulary and acupuncture. The present article supplies the first English-language translation of its contents along with a brief introduction.
\end{abstract}

\section{Introduction}

While repairing an irrigation system in November 1972, farmers discovered a vaulted tomb in Hantanpo 旱灘坡, $10 \mathrm{~km}$ from Wuwei 武威 city in Gansu province, dating to the early Eastern Han dynasty (25-220 C.E.). Judging from the fact that a staff with a pigeon top was placed in front of the coffin, the tomb occupant, whose name is lost to us, was probably over the age of seventy sui 歲. Outside of the coffin were seven grave goods made of earthenware, including pots ( $h u$ 菛), miniature warehouses (cang 倉), stoves (zao 灶), wells (jing 井), and dishes (pan 盤). Within the coffin were coins and two beads. ${ }^{1}$ At the head of the tomb occupant's corpse was a hemp bag containing seventy-eight documents, bundled together. Upon examination, archaeologists determined that the bulk of the documents contained contents related to drug formulary. The sheer number of formulas discussed in the documents makes this site incomparable for the Eastern Han period. Yet, despite its importance, scholars have largely overlooked the find, particularly in comparison to the medical manuscripts recovered from the Mawangdui 馬王堆 site (с. 168 в.C.E). In the four decades since the publication of the complete transcription, only a handful of works on the Wuwei documents exists. These include studies by Akahori Akira 赤堀昭 and Yamada Keiji

\footnotetext{
* Yong Yang, 楊勇, Yuelu Academy, Hunan University; email: whdxyy2006@163.com; Miranda Brown 董慕達, University of Michigan; email: mdbrown@umich.edu.

1. Gansusheng bowuguan 甘肅省博物館 and Gansusheng Wuweixian wenhuaguan 甘肃省武威縣文化館, “Wuwei Hantanpo Hanmu fajue jianbao一chutu dapi yiyao jiandu" 武威旱灘坡漢墓發掘簡報——出土大批醫藥簡牘, Wenwu 文物 1973.12, $18-22 ; 18,21$.
}

(c) The Society for the Study of Early China and Cambridge University Press 2017 
山田慶兒 (1985), He Shuangquan 何雙全 (1986), and Zhang Yanchang 張 延昌 (2006); ${ }^{2}$ and a volume of essays, edited by Li Shenghua 李盛華 and Zhang Yanchang, published in 2014. ${ }^{3}$ No full-length studies or essays on the subject have been published in a Western language, a lacuna that the present article seeks to fill with a brief introduction and translation.

\section{The Archaeological Context}

Unlike other well-known Qin and Han finds, much of the archaeological context of the Wuwei manuscripts, discovered during the Cultural Revolution, is lost to us. Archaeologists have yet to identify the tomb in which the documents were discovered. However, the following facts are known. At the time of the site report's publication in the 1973 issue of Wenwu 文物, archaeologists believed that the tomb was part of a cluster of six to seven Han-dynasty burials. These burials were proximate to another larger cluster of about forty Han-dynasty tombs at the Mozuizi 磨咀子 site, approximately twenty-five kilometers away. ${ }^{4}$

While the exact spatial coordinates of the site are currently unknown, the site report reveals the following about the tomb's characteristics and dimensions. Archaeologists classified the burial as a single chamber tomb (tudong danshi 土洞單室). The front of the tomb's door was connected through a sloped path (xiepo mudao 斜坡墓道). The door and chamber of the tomb were both flat top (pingding 平頂). The door of the tomb also used large gravel (dalish $i$ 大礫石) as a seal. From top to bottom, the tomb chamber measured $4 \mathrm{~m}$. The door of the tomb was $1.0 \mathrm{~m}$ in height, $0.72 \mathrm{~m}$ in width, and $0.6 \mathrm{~m}$ in depth. The tomb was furthermore oriented $60^{\circ}$ to the East. The coffin was $3.4 \mathrm{~m}$ from East to West, $1.25 \mathrm{~m}$

2. Gansusheng bowuguan 甘肅省博物館 ed., Wuwei Handai yijian 武威漢代醫簡 (Beijing: Wenwu, 1975). For Akahori Akira 赤堀昭 and Yamada Keiji 山田慶兒, Shinhatsugen Chūgoku kagakushi shiryō no kenkyu u 新發現中國科學史資料の研究 (Kyoto: Kyōto Daigaku Jinbun Kagaku Kenkyūjo, 1985), 363-404. The translation was based on Akahori's earlier translation, “Bu-i Kandai ikan ni tsuite” 武威漢代醫簡について, Tōyo Gakuhō 東方學報 50 (1978), 75-107. He Shuangquan 何隻全, “Wuwei Handai yijian shiwen buzheng" 武威漢代醫簡釋文補正, Wenwu 文物 1986.4, 39; Zhang Yanchang 張 延昌, Wuwei Handai yijian zhujie 武威漢代醫簡注解 (Beijing: Zhongyi, 2006). For passing discussion of the Wuwei manuscripts, see Xie Guihua, "Han Bamboo and Wooden Medical Records Discovered in Military Sites from the North Western Frontier Regions," in Medieval Chinese Medicine: The Dunhuang Medical Manuscripts, ed. Vivienne Lo and Christopher Cullen (London: RoutledgeCurzon, 2005), 77-105.

3. Li Shenghua 李盛华 and Zhang Yanchang 張延昌, eds., Wuwei Handai yijian yanjiu jicheng 武威漢代醫簡研究集成 (Hefei: Anhui kexue jishu, 2014).

4. Gansusheng bowuguan and Gansusheng Wuweixian wenhuaguan, "Wuwei Hantanpo," 18. 
from North to South, and $1.1 \mathrm{~m}$ in height. ${ }^{5}$ By the time that the tomb was discovered, the corpse, which had been laid supine, had decayed, although some of the skeleton remained. Based on the surviving remains, archaeologists determined that the tomb occupant had been male. ${ }^{6}$ Based on the presence of documents with medical contents, Luo Fuyi 羅福頣 furthermore conjectured that the tomb occupant had been a doctor. This identification, however, is speculative. 7

\section{The Strips and Tablets: an Overview of the Manuscripts}

When archaeologists recovered the manuscripts, they discovered that the documents had been affected by the corpse's decay and were partially rotten, incomplete, and unclear. ${ }^{8}$ The documents were furthermore in a state of disarray, making it difficult for the archaeologists to reconstruct the contents. ${ }^{9}$

At present, there are 92 strips (jian 簡) and tablets (mudu 木牘). ${ }^{10}$ Of those, 78 are strips and 14 are tablets. The strips were composed of wood from pine and poplar, two common materials used to make documents in the Northwest. The strips had writing only on one side. Of the strips, about sixty were complete. The average length of the strips was between 23.0 and $23.4 \mathrm{~cm}$. The strips also lacked numbers. The archaeologists divided the strips into two categories (lei 類) based on the width of the strips and the remnants of the binding cord. ${ }^{11}$

The strips from the first category (strips 3-41) were one centimeter in width, and notches were cut into the sides (qiekou 鐟 $\square$ ). The strips were connected by three binding cords, traces of which can still be

5. Gansusheng bowuguan and Gansusheng Wuweixian wenhuaguan, "Wuwei Hantanpo," 22-23.

6. Gansusheng bowuguan and Gansusheng Wuweixian wenhuaguan, "Wuwei Hantanpo," 18-19.

7. Luo Fuyi 羅福頣, “Dui Wuwei Han yiyaojian de yidian renshi” 對武威漢醫藥簡 的一點認識, Wenwu 1973.12, 30-31; 31.

8. Gansusheng bowuguan and Gansusheng Wuweixian wenhuaguan, "Wuwei Hantanpo," 19.

9. Gansusheng bowuguan and Gansusheng Wuweixian wenhuaguan, "Wuwei Hantanpo," 19.

10. We find it useful to distinguish between strips (jian) and tablets ( $m u d u)$, despite the fact that the two could be composed of similar materials. At the Wuwei Hantanpo site, the strips (jian) were made of wood, like most strips found in the Northwest. However, in other areas of China, particularly in the south, the strips were made of bamboo. The main differences between the strips (jian) and tablets (mudu) discovered at Wuwei lie in their width, as well as the fact that writing was found on both sides of the tablets.

11. Gansusheng bowuguan and Gansusheng Wuweixian wenhuaguan, "Wuwei Hantanpo," 19. 
detected. In the first category, 41 strips were preserved. Among these, more than 30 were whole or partially intact. Each strip had about 35 characters on it. ${ }^{12}$

The strips placed in the second category (strips $42-78$ ) by the authors of the site report were narrower, being half a centimeter in width. The sides of these strips lacked notches. The strips in this category totaled 37 in number, and each strip had approximately 37 characters and was bound with three binding cords..$^{13}$

The authors of the site report surmised that the strips were ordered and bound together before text was written on them. Because of their overlapping contents, the authors inferred that the two categories of strips originally belonged to the same text. ${ }^{14}$ Yet this view has its drawbacks and overlooks certain features of the manuscripts, something pointed out by the authors of the site report. For example, such a view neglects the fact that the two categories differed in terms of the width of the strips, as well as the placement of the binding cords. ${ }^{15}$

According to the authors of the site report, the tablets were mostly composed of pinewood. On all but two of the tablets, writing appeared on both sides. The tablets moreover were wider than the strips; the tablets range between 1.1 and $4 \mathrm{~cm}$ in width. The tablets were between 22.7 and $23.9 \mathrm{~cm}$ in length and between 0.2 and $0.6 \mathrm{~cm}$ in thickness. The tablets furthermore lacked any trace of binding. ${ }^{16}$

\section{The Writing}

The documents were written mostly in clerical script (lish $u$ 隸書), with the minority of the contents rendered in cursive (caoshu 草書). ${ }^{17}$ In terms of handwriting, we could detect three distinct styles (one of which was rendered in caoshu). Yet it is unclear whether these styles represented the hands of three different scribes or the handwriting of a single person at different periods of time.

12. Gansusheng bowuguan and Gansusheng Wuweixian wenhuaguan, "Wuwei Hantanpo," 19.

13. Gansusheng bowuguan and Gansusheng Wuweixian wenhuaguan, "Wuwei Hantanpo," 19.

14. Gansusheng bowuguan and Gansusheng Wuweixian wenhuaguan, "Wuwei Hantanpo," 19.

15. Gansusheng bowuguan and Gansusheng Wuweixian wenhuaguan, "Wuwei Hantanpo," 19.

16. Gansusheng bowuguan and Gansusheng Wuweixian wenhuaguan, "Wuwei Hantanpo," 19.

17. Gansusheng bowuguan and Gansusheng Wuweixian wenhuaguan, "Wuwei Hantanpo," 20. 
In terms of orthography, there were many instances of phonetic borrowings (tongjia $z i$ 通假字) and graphic variants (yiti zi 異體字). Examples of phonetic borrowings include shi 矢 for shi 屎 (strip 18). For variants, we found numerous examples such as the substitution of yong 急 for tong 痛 (strip 11) and jiu 条 for jiu 尒 (strip 21). ${ }^{18}$ Also, we found variants such as $b u f u$ 不复 for $b u f u$ 不復 on strips 48 and 59. In only a few cases, we found unambiguous evidence of scribal error. For example, on strip 6, the character for five (wu 五) was written for six (liu 六).

\section{Contents}

With the exception of tablet 92, the contents of the strips and tablets are medical in nature. We can further divide the subject of the documents into three kinds: medical formulas, acupuncture (and restrictions on acupuncture), and a fragmentary register of purchased materia medica. With respect to the formulas, the contents are practical as opposed to theoretical; they relate the substances and preparation methods for remedies and say little about the etiology of illnesses.

The formulas reference a wide range of materia medica. By one account, the substances mentioned in the manuscripts include 63 herbs, 12 animal products, 16 minerals, and 9 substances that could not be categorized. ${ }^{19}$ Of these, 69 of the one hundred substances mentioned in the Wuwei documents also appear in the Shennong bencao jing 神農本草經; another 11 are found in the Mingyi bielu 名醫别錄. Another 20 substances are not found in either classic of pharmacopoeia. The Wuwei manuscripts also include materia medica local to the Northwest: the excrement of herd animals, such as white sheep (baiyang shi 白羊屎). ${ }^{20}$

18. In treating these and other examples as variants rather than as errors (wuxie 誤 寫), we follow William G. Boltz, "Orthographic Variation in Early Chinese Manuscripts," Acta Orientalia Academiae Scientiarum Hungaricae 62.1 (2009), 89-113; Boltz, "Character Variation in Early Chinese Manuscripts," Manuscript Cultures 5 (2012/2013), 76-83. Boltz also draws on the findings of Matthias Richter, "Towards a Profile of Graphic Variation: On the Distribution of Graphic Variants within the Mawangdui Laozi Manuscripts," Asiatische Studien/Études Asiatiques 59 (2005), 169-207.

19. Gansusheng bowuguan ed., Wuwei Handai yijian, 27. This claim is at variance from what was reported earlier by the Zhongyi yanjiuyuan yishi wenxian yanjiushi 中 醫研究院醫史文獻研究室, “Wuwei Handai yiyao jiandu zai yixueshi shang de zhongyao yiyi" 武威漢代醫藥簡牘在醫學史上的重要意義, Wenwu 1973.12, 23-29; 24, 26. We follow what appears in the 1975 publication by the same research team, which seems to have been a revision of the earlier essay.

20. Zhongyi yanjiuyuan yishi wenxian yanjiushi, "Wuwei Handai yiyao jiandu zai yixueshi shang de zhongyao yiyi," 28. 


\section{The Structure of the Formulas}

The vast majority of the formulas found in the Wuwei documents follow a set pattern, suggesting a high degree of standardization. The general pattern is depicted in Figure 1. Figure 2 shows the contents of tablet 82. As we can see from Figure 2, the characters at the formula's beginning could not be transcribed in whole, but it is clear that the text begins with the name of the formula, which reflects the nature of the ailment. Then comes the seven substances to be used and their quantities. Next follows the preparation of the medicinal substances (specifically, the processing of all seven substances and the use of honey to combine the mixture into a pellet) and the methods of administration (the medicine is to be taken

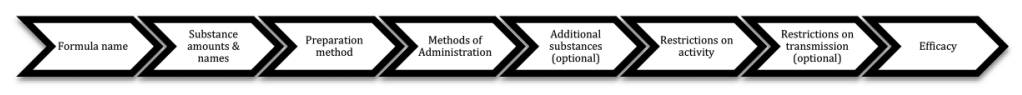

Figure 1 Structure of the Wuwei formulas. Figure drawn by authors.

\begin{tabular}{|c|c|}
\hline Part & Text \\
\hline Formula name & $\begin{array}{l}\text { A formula to treat chronic diarrhea, leaking abdomen where } \\
\text { there is blood [and pus] letting in the stool (?) [4 illegible } \\
\text { characters and } 4 \text { more untranslatable characters] ... cases of } \\
\text { illnesses that healers cannot treat and all refuse to see: }\end{array}$ \\
\hline Substance Amounts \& Names & $\begin{array}{l}\text { Four fen of Golden Thread [Coptis chinensis]. } \\
1 \text { fen each of: Baical skullcap; Halloysite, fossil bones, ginseng, } \\
\text { ginger root, and cassia twigs. }\end{array}$ \\
\hline Preparation methods & $\begin{array}{l}\text { Pulverize and combine all seven of these substances, making } \\
\text { pellets as large as crossbow pellets with honey. }\end{array}$ \\
\hline Methods of Administration & Before supper, drink one pellet of medicine with congee. \\
\hline Additional substances & $\begin{array}{l}\text { If there is no improvement [ } 4 \text { illegible characters]. } \\
\text { If there is [ } 1 \text { illegible character] in the abdomen, add } 2 \text { fen of } \\
\text { licorice. } \\
\text { If there is a lot of blood, add } 2 \text { fen of cassia twigs. } \\
\text { If there is a lot of pus, then add } 2 \text { fen of Halloysite ... [ } 7 \text { illegible } \\
\text { characters and } 2 \text { untranslatable characters] ... add one fen of } \\
\text { Baical skullcap. }\end{array}$ \\
\hline Restrictions on activity & One is prohibited from eating fresh fish or pork. \\
\hline Restriction on transmission & Proscribed formula \\
\hline Efficacy & Efficacious \\
\hline
\end{tabular}

Figure 2. An Analysis of a Wuwei Formula (tablet 82). With the exception of providing additional information for atypical symptoms, the formula above follows the pattern found in the rest of the corpus. 
before supper, and one pellet should be administered with congee). At this point, the formula deviates from the pattern found elsewhere in the manuscripts and adds provisions for additional symptoms. The text further mentions proscribed foods and restrictions on transmission before concluding with comments about the formula's efficacy.

Insofar as the formulas follow a single format, the Wuwei manuscripts stand apart from other early collections. Most of the others-notably, those uncovered at the Zhoujiatai 周家臺 site (c. 209-206 в.C.E.), Liye 里耶, and Mawangdui-do not follow a uniform format. ${ }^{21}$ (The Liushazhui 流沙墜 strips, dating to the Han dynasty and also from the Northwest, were similar to those uncovered at Wuwei insofar as they too conformed to a set pattern. ${ }^{22}$ ) The Wushier bingfang 五十二病方, from Mawangdui, provides a case in point. As Figures 3 and 4 reveal, the formulas in that collection have different structures. ${ }^{23}$

\section{Comparison of Contents}

The authors of the Wuwei manuscripts emphasized precise dosage, a feature first seen in the newly discovered Laoguanshan 老官山 site (dat-

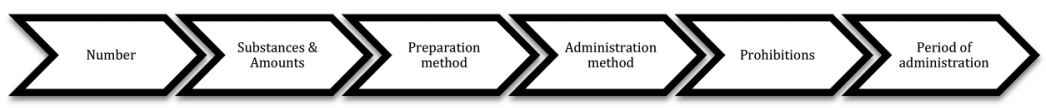

Figure 3. One format of the formulas from the Wushier bingfang. Picture drawn by authors.

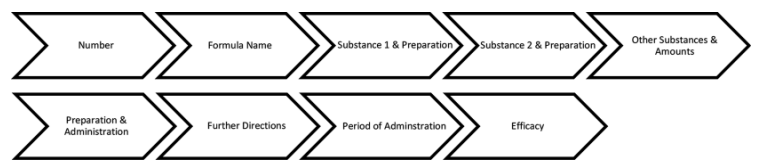

Figure 4. An alternate format of the formulas from the Wushier bingfang. Unlike the formulas from Wuwei, those in the Wushier bingfang do not conform to a single format. Picture drawn by authors.

21. For examples of formulas that exhibit different formats from those found at the Wuwei site, see Chen Wei 陳偉 et al., Liye Qin jiandu jiaoshi 里耶秦簡牘校釋 (Wuhan: Wuhan daxue chubanshe, 2012), vol. 1, 270.

22. See the examples of formulas for persistent coughs and saddle wounds in Luo Zhenyu 羅振玉 and Wang Guowei 王國維, Liushazhui jian 流沙墜簡 (Beijing, Zhonghua, 1993), 23.

23. For Figure 3, see Qiu Xigui 雸錫圭, ed., Changsha Mawangdui Hanmu jianbo jicheng 長沙馬王堆漢墓簡帛集成 (Beijing: Zhonghua shuju, 2014), vol. 5, 219 (23); Donald Harper, Early Chinese Medical Literature (London: Kegan Paul, 1998), 227-28. For Figure 4, see Changsha Mawangdui Hanmu jianbo jicheng, vol. 5, 284 (385-75); Harper, Early Chinese Medical Literature, 292-93. 
ing to the second century в.с.Е.). ${ }^{24}$ The formulas make use of a wide range of measurements for weight and volume. Common examples include fen 分 (used for weight), as well as liang 兩 and sheng 升 (13.8 g and $200 \mathrm{ml}$ respectively for the Eastern Han dynasty). For a typical example, consider one excerpt from the Wuwei site:

治目恿方：以春三月上旬治藥。曾青四兩, 载鹽三兩, 皆冶合, 以乳汁 和, 盛以銅器, 以傅目, 良。16

A formula to treat eyes in pain: In the first ten-day period of the three months of spring, make a medicine: four liang [55.2 g] of Malachite or Laminar, and three liang [41.4 g] of Turkestan Salt. Pulverize and combine all of these, mixing together with milk and filling it in a bronze utensil. Use this to apply to the eyes. Efficacious.

In this regard, the Wuwei and Laoguanshan manuscripts stand apart from other excavated works of materia medica. Those found at Zhoujiatai, Liye, and Mawangdui, for example, tend to be vague about quantities. Admittedly, we find a few references in these corpuses to precise measurements, for example to sheng. More typical, however, is the following excerpt, taken from the Liye site:

七・暴病心痛灼灼者, 治之：析蓂实, 冶, 二; 枯橿、菌桂, 冶, 各 一。凡三物并和, 取三指最到节二, 温醇酒

Number seven. To treat those stricken with a violent eruption of heart pain that burns: Pulverize two seeds of Penny-cress [Thlaspi arvense]. Pulverize one dried ginger [Zingiber officinale] and one Cassia twig [Cinnamomum cassia]. Mix all three of these substances. Take a three-finger pinch, knuckle deep with warm, fine alcohol with a strong flavor. 25

24. Zhao Huaizhou 趙懷舟, He Zhongjun 和中浚, Li Jiming 李繼明, Zhou Xinglan 周興蘭, and Xie Tao 謝濤, “Chengdu Laoguanshan Hanmu 'Liushi bingfang' he “Wuwei Handai yijian' de bijiao yanjiu," 成都老官山漢墓《六十病方》和《武威漢代醫 簡》的比較研究, Zhongyiyao wenhua 中醫藥文化 2015.5, 4-9; 7. For precise units of measurement, see Liu Xinglong 劉興隆,Zhao Huaizhou 趟懷舟, Zhou Xinglan 周興蘭, and He Zhongjun 和中浚, “Chengdu Laoguanshan Hanmu chutu yijian 'Liushi bingfang' fangji jixing kaobian” 成都老官山漢墓出土醫簡《六十病方》方劑劑型考辨, Zhongyiyao wenhua 中醫藥文化 2016.1，4-14; 9. For the site report, see Chengdu wenwu kaogu yanjiusuo, 成都文物考古研究所 and Jingzhou wenwu baohu zhongxin 荊州文物保護 中心, “Chengdushi Tianhuizhen Laoguanshan Han mu” 成都市天回鎮老官山漢墓, Kaogu 考古 2014.7, 59-70.

25. Chen Wei et al., Liye Qin jiandu jiaoshi, vol. 1, 293. Translation adapted from Miranda Brown, Art of Medicine in Early China: The Ancient and Medieval Origins of a Modern Archive (New York: Cambridge University Press, 2015), 80. 
The author of the formula did not feel the need to specify the amount of ginger in terms of weight or volume. Instead, he merely indicated the number of seeds and pieces of ginger. It is only at the end of the formula that we see anything approximating a standard quantity (a three-finger pinch), but that measurement, which varies according to the size of the maker's fingers, is still less specific than the units of measurement discussed in later texts, such as a square-inch spoonful (fangcun bi 方寸七), which can be rendered down to the milliliter.

\section{Divination, Exorcism, and Divine Intervention}

The Wuwei manuscripts offer a contrast to other early excavated manuscripts in another respect: we find no trace of exorcism and other techniques used to mitigate the malevolent influence of spirits and other divine beings. Instead, the former set of manuscripts focuses on treating illnesses exclusively through the administration of drug formulary, external pastes, and, to a lesser extent, acupuncture. In this respect, the Wuwei manuscripts are a far cry from earlier finds, particularly those seen at Zhoujiatai and Mawangdui. There, one sees plentiful references to the "Pace of $\mathrm{Yu}$ " (Yu bu 禹步), a ritual step used to avoid various hazards and misfortunes, such as disasters or illnesses associated with spirits and demons. ${ }^{26}$

\section{Forbidden Formulas}

The prohibitions in the Wuwei manuscripts represent another noteworthy feature. The manuscripts contain at least two kinds of prohibitions. The first are restrictions on activities and foodstuffs during the period of a medicine's administration. These include the consumption of fish, pork, spicy foods, and alcohol, as well as activities such as sexual conduct, physical exertion, and exposure to wind. These restrictions are similar to those of the Wushier bingfang. The second are prohibitions on transmission, as in the following excerpt:

】飲食, 數驗, 禁, 不傳也・74

[Indeterminate number of missing characters] ... Eat and drink.

Repeatedly tested. Proscribed; do not transmit.

While attested in the received literature, unambiguous evidence of restriction on transmission is absent from most medical manuscripts

26. On this point, see the discussion in Harper, Early Chinese Medical Literature, 168-69. The Qin strips kept at the Peking University Museum also include exorcistic or spiritual methods. On this point, see Chen Kanli 陳㑆理, “Beida Qin jian zhong de fangshu shu 北大秦簡中的方術書," Wenwu 文物 2012.6, 90-96; 94. 
(notably those from Mawangdui). ${ }^{27}$ We do however find one parallel to the restrictions found at Wuwei in a published fragment from the recently discovered Laoguanshan find: ${ }^{28}$

五十七。治血暴發者: 屑土瓜二枚, 蒙菌、圭各一, 取一篇, 温美酒半 升。莫勿食, 旦飲之, 日一, 五日已。禁。

Number 57. To treat blood that bursts forth abruptly. Mince two pieces of tugua [i.e., some kind of unidentified tuber], and one each of mengjun [an unidentified substance] and cassia twig. Take one yue [10 ml] of the medicine with one half sheng [100 ml] of warm, fine alcohol. Do not eat at dusk. Drink it in the morning once a day. In five days, the illness will come to an end. Proscribed. ${ }^{29}$

\section{Attribution of Formulas}

The Wuwei manuscripts attribute formulas to several figures. These include a Mr. Lu (Lu shi 魯氏 on strip 43), Mr. Gongsun (Gongsun jun 公 孫君 on tablet 83), possibly Gongsun Guang 公孫光; ${ }^{30}$ the Lord of the White Waters (Baishui hou 白水侯 on tablet 84); the Lord of Donghai 東 海侯 (Donghai hou on tablet 84); Mr. Lü Gong (Lü Gong jun 呂功君 on tablet 42); and General Geng of Jianwei (Jianwei Geng jiangjun 建威耿將 軍), probably Geng Yan 耿畣 (3-58 C.E., on tablet 85 ).

In this regard, the Wuwei manuscripts follow a pattern. Published excerpts from the looted manuscripts at the Peking Museum also attribute formulas to individuals—-for example to Mr. Qin (Qinshi 秦氏, possibly a reference to Bian Que or Qin Yueren 秦越人), Ling You 泠游, and

27. On this point, see Nathan Sivin, "Text and Experience in Classical Chinese Medicine," in Knowledge and the Scholarly Medical Traditions, ed. Don Bates (Cambridge: Cambridge University Press, 1995), 177-204; Li Jianmin 李建民, “Zhongguo gudai jinfang kaolun” 中國古代 “禁方” 考論 in Shengmingshixue—cong yiliao kan Zhongguo lishi 生命史學一一從醫療看中國歷史 (Taipei: Sanminshuju, 2005), 149-206. See Harper, Early Chinese Medical Literature, 65-66. We would like to note that Wushier bingfang contains twelve references to wujin 冊禁. It is unclear to us whether this phrase refers to the absence of any restrictions on food or activities as opposed to restrictions on transmission. Harper translates wujin as "there are no prohibitions," meaning no restrictions on activity or diet. For an example, see Harper, Early Chinese Medical Literature, 236.

28. For prohibitions, see Zhao et al., "Chengdu Laoguanshan Hanmu," 7.

29. Chengdu wenwu kaogu yanjiusuo and Jingzhou wenwu baohu zhongxin, "Chengdushi Tianhuizhen Laoguanshan Han mu," 64.

30. For the identification of Mr. Gongsun and General Geng of Jianwei, see Chen Zhi 陳直, Wenshi kaogu luncong 文史考古論叢 (Tianjin, Tianjin guji, 1988), 300-302; also see Akahori and Yamada, Shinhatsugen Chügoku kagakushi shiryō no kenkyū, 395, n. 236. 
Weng Yi 翁壹. ${ }^{31}$ In contrast, the Zhoujiatai or Mawangdui manuscripts do not attribute formulas to some authority figure or historical personage.

\title{
Conventions of Translation and Interpretative Problems
}

\author{
Transcription
}

Our transcription was made on the basis of the photographs supplied in Wuwei Handai yijian 武威漢代醫簡 (Beijing: Wenwu, 1975). We have made every effort to transcribe the characters as they appeared on the original strips, including non-standard graphs and punctuation marks. Where possible, we also consulted the color photographs of a handful of the tablets published in Hexi jiandu 河西簡牘 (Chongqing: Chongqing, 2002). In addition, we have provided our annotations of non-standard graphs, phonetic loans, variant characters, and errors in the footnotes. We furthermore left a blank box $\square$ where we could not transcribe a character due to the fact that the character was illegible. In cases where the text was broken, we have added a box containing a cross $\square$. In some cases, our transcription of a graph is tentative. We have marked such characters in brackets [] and explained our reasoning in a note.

Furthermore, we encountered several instances in which the scribes employed punctuation markers. For a comma , we marked a $\bullet$ in the transcription; for a long comma $\mathbf{l}$, we added a I. In some cases, the scribe used a ditto mark to indicate that a character was to be duplicated. In those instances, we used an equal sign $=$ to denote the presence of such a mark. We also added the duplicated character in parentheses ().

We have also consulted the transcriptions made by the editors of the Wuwei volume (hereafter the Wuwei editors), Akahori Akira and Yamada Keiji, He Shuangquan 何隻隻全, and Zhang Yanchang. In cases where our transcriptions departed from those of previous scholars, we noted this in the footnotes. Finally, we added our own punctuation to the text.

\section{Identification of Substances and Weights and Measures}

For the identification of materia medica, we primarily followed the translations provided by Shiu-ying $\mathrm{Hu}$ in An Enumeration of Chinese Materia Medica, 2nd edition (Hong Kong: Chinese University Press, 1999). In cases where $\mathrm{Hu}$ does not offer an identification, we consulted Nathan Sivin's Chinese Alchemy: Preliminary Studies (Cambridge, MA: Harvard University Press, 1968), Penelope Barrett's Appendix in Vivienne Lo and

31. Beijing daxue chutu wenxian yanjiusuo 北京大學出土文獻研究所, “Beijing daxue cang Xi Han zhushu gaishuo" 北京大學藏西漢竹書概說, Wenwu 文物 2011.6, $49-57 ; 55$. 
Christopher Cullen, eds., Medieval Chinese Medicine: The Dunhuang Medical Manuscripts (London: Routledge, 2009), and Bernard E. Read's Chinese Medicinal Plants from the Ben Ts'ao Kang Mu A.D. 1596, 3rd edition (Peking: Peking Natural History Bulletin, 1936). Occasionally, we encountered substances that could not be identified, as no parallels are attested in received texts. These include substances like mendong 門冬 (tablet 8o). In such cases, we have chosen to simply transliterate the characters without translation. It bears emphasis, however, that the exact identification of botanical, zoological, or mineral substances remains uncertain, something previously noted by Donald Harper and Paul Unschuld. ${ }^{32}$ Indeed, scholarly opinion sometimes divides on the identification of substances in the Wuwei corpus, so readers should treat the translations of pharmacological agents as tentative identifications.

\section{Loans, Variants, and Phonetic Borrowings}

With respect to identifying phonetic loans, orthographic variants, and errors, we draw upon the work of the Wuwei editors, Akahori and Yamada, and Zhang Yanchang. For phonetic loans, we checked the identifications proposed by previous scholars such as Akahori and Yamada, and especially Zhang Yanchang, against several sources. These include the Guwenzi tongjia shili 古文字通假釋例, by Wang Hui 王輝 (Taipei: Yiwen yinshuguan, 1993), and the reconstructions for the Later Han (hereafter LH) in Minimal Old Chinese and Later Han Chinese: A Companion to Grammata Serica Recensa by Axel Schuessler (Honolulu: University of Hawai' $i$ Press, 2009). Additionally, we consulted the eminent linguist William Baxter, who checked published reconstructions, evaluated whether characters could be substituted for each other, and reconstructed the phonology of characters not found in Minimal Old Chinese.

It bears mentioning that we often diverge from the opinions of earlier scholars who have identified errors and phonetic loans, especially Zhang Yanchang (who identifies many errors and phonetic loans). Based on recent work in paleography, we are mindful of the difficulty of differentiating between variants and errors before the establishment of an orthographic standard. ${ }^{3}$ We further acknowledge the difficulty of

32. On this problem, see Paul Unschuld and Zhibin Zhang, Dictionary of the Ben cao gang mu, Volume 1: Chinese Historical Illness Terminology (Ben Cao Gang Mu Dictionary Project) (Berkeley: University of California Press, 2014), 10; Donald Harper, Early Chinese Medical Literature, 99-101.

33. On this point, see particularly Boltz, "Orthographic Variation" and Matthias Richter, "Towards a Profile of Graphic Variation." Also see Imre Galambos, Orthography of Early Chinese Writing: Evidence from Newly Excavated Manuscripts (Budapest: Department of East Asia Studies, 2006). 
distinguishing phonetic loans from graphic variants in early manuscripts. The occurrence of cai 采 (to gather) on strip 30 illustrates this problem. The Wuwei editors, Akahori and Yamada, and Zhang Yanchang interpret this graph as cai 菜 (vegetables). ${ }^{34}$ As in most cases, the Wuwei editors and Akahori and Yamada do not supply a rationale for interpreting the graph this way, most likely because they believed that it was obvious that the former was a variant of the latter. Zhang Yanchang, however, claims that cai 采 (Schuessler $4-44<\mathrm{LH}^{*} \mathrm{ts}^{\mathrm{h}} \partial^{\mathrm{B}}$ ) was a phonetic loan for cai 菜 (Schuessler 4-44> LH ${ }^{*} \mathrm{ts}^{\mathrm{h}}{ }^{\mathrm{c}}$ ). 35 Similarly, Zhang Yanchang asserts that $z h i$ 直 (Schuessler 5-12< LH * dik), appearing in tablets 91 A91B, was a phonetic loan for zhi 值 (Schuessler $5-12<\mathrm{LH}{ }^{*}{ }^{*} a^{\mathrm{c}}$ ). ${ }^{36}$ While Zhang is correct about the closeness of the pronunciation in both cases, we wonder about the wisdom of labeling such graphs "loans." Ancient scribes often substituted characters containing the same phonetic element but with different radicals. Indeed, the Wuwei scribe or scribes frequently substituted graphs with similar phonetic elements, and sometimes used more than one variant in the same text. Examples of this include writing yong 息 (strips 12, 13, 15, etc.) and yong 慂 (strip 52) for tong 痛. In light of this, we have decided to reserve the label "phonetic loans" for instances in which two characters probably had similar or identical pronunciations, but were composed of different phonetic elements. In cases where the characters differed only in terms of their radical, we have chosen to refer to these substitutions as variants.

For weights and measures, we followed the values given by the Hanyu da cidian 漢語大詞典. Our readings have been supplemented by $\mathrm{Wu}$ Chengluo 吳承洛, Zhongguo duliang hengshi 中國度量衡史 (Shanghai: Shangwu yinshuguan, 1937, rpt. 1957). We also consulted Zhongguo gudai duliang heng 中國古代度量衡 (Beijing: Keji, 1992) by Qiu Guangming 丘光明.

\section{Differences in Interpretation}

For our translation, we have consulted a range of opinions. The major works on the subject include those by the Wuwei editors, Akahori and Yamada, and Zhang Yanchang. The Wuwei editors provide their transcription of the strips and tablets without punctuation; Akahori and Yamada Keiji and Zhang Yanchang offer their transcriptions and punctuation of the text. Akahori and Yamada also translate the text into

34. Gansusheng bowuguan, Wuwei Handai yijian, 6; Akahori and Yamada, Shinhatsugen Chügoku kagakushi shiryō no kenkyū, 376.

35. Zhang Yanchang, Wuwei Handai yijian zhujie, 121, n. 5.

36. Zhang Yanchang, Wuwei Handai yijian zhujie, 139, n. 1. 
modern Japanese. The three existing interpretations of the text differ from each other at points, although Akahori and Yamada follow the Wuwei editors closely in terms of transcription. Akahori and Yamada and Zhang Yanchang, for example, often disagree on punctuation. Moreover, we have considered the interpretations on specific points offered by other scholars, such as He Shuangquan.

In preparing our translation, we made efforts to identify all major differences of opinion with respect to transcription, punctuation, and the identification of substances and technical vocabulary. We also explain our departures from previous interpretations, as well as our reasons for selecting one interpretation over another.

Our reasoning reflects two general principles: (1) consistency (this is important when interpreting antonyms or words used interchangeably); and (2) parallelism (the assumption that words found in the same place, either within a single formula or a collection of formulas, are equivalent units).

In this regard, we provide two examples where our interpretations diverged significantly from previous scholarship. For example, both Akahori and Yamada and Zhang Yanchang interpret the copious references to fen 分 as "equal proportions" (dengfen 等份) as opposed to a unit of weight measurement. Akahori and Yamada Keiji assert, "Fen is not a unit of weight, but refers instead to the proportion of the medicinal substances." 37 Similarly, Zhang Yanchang annotates the first reference to fen on strip 3, writing, "This is not actually fen as in the unit of weight measurement but rather proportion." ${ }^{8} \mathrm{He}$ adds that most of the strips and tablets use fen in this way. Akahori, Yamada, and Zhang Yanchang draw upon an old interpretation of fen, promoted by Luo Zhenyu 羅振玉 (1866-1940) and Wang Guowei 王國維 (1877-1922) in the early twentieth century. Their interpretation of fen was based on a limited set of sources and reflected a still older view, found in the commentary to the Bencao jing, which observes, "Ancient balances only had $z h u$ and liang [as units of measurement] and did not have the appellation of $f e n$ "古秤唯有銖两 而無分名. This interpretation has been challenged by Qiu Guangming 丘 光明, Qiu Long 邱隆, Yang Ping 楊平, and Lu Jiaxi 盧嘉錫, who show through their examination of received texts that fen was, in fact, a measurement of weight by the third century C.E. 39

37. Akahori and Yamada, Shinhatsugen Chūgoku kagakushi shiryō no kenkyū, 365, n. 8.

38. Zhang Yanchang, Wuwei Handai yijian zhujie, 113, n. 5 .

39. Bencao jing jizhu 本草經集注, ed. Tao Hongjing 陶弘景 and Shang Zhijun 尚志鈞 (Beijing: Renmin weisheng, 1994), 36. Qiu Guangming 丘光明, Qiu Long 邱隆, Yang Ping 楊平, and Lu Jiaxi 盧嘉錫, Zhongguo kexue jishu shi:duliangheng juan 中國科學技術 史：度量衡卷 (Beijing: Kexue, 2001), 338-39, esp. 338. 
The view of fen promoted by Akahori, Yamada, and Zhang Yanchang is untenable; not only is it inconsistent with the principles of parallelism and consistency but it does not mesh with other examples of fen's usage in the corpus. For example, consider the following excerpt from Wuwei:

治奶人膏藥方: [樓]三升, 當歸十分, 白茞四分, 付子世枚, 甘草七分, 弓大倠十分, 菒草二束 $88 \mathrm{~A}$

A formula for a medicinal paste to treat women:

[Unknown quantity], 3 sheng [6oo ml].

Chinese Angelica, 10 fen.

Fragrant Angelica, 4 fen.

Szechuan aconite root, 30 pieces (mei).

Licorice, 7 fen.

[3 untranslatable characters, including one non-standard graph], 1o fen.

Chinese lovage [Ligusticum sinense or L. jeholense], 2 bundles.

Here, fen appears alongside other units of measurement (sheng for volume, mei for the number of pieces, and shu for bundles), thereby making it unlikely that fen meant "equal proportions." What is more, other Han-dynasty texts from the Northwest use fen and liang in the same formula, which further suggests that fen must be a unit of measurement. The Maquanwan 馬圈灣 site, also from the Northwest, for example, contains the following formula:

\section{良口治 $\square$ 善者一两，李石十分，人参十分取善者。}

Efficacious ... [1 illegible character] treat ... one liang [13.8 g] of good quality [1 illegible character], 10 fen of lishi [i.e., an unknown substance], and 10 fen of high-quality ginseng [Panax ginseng]. $4^{\circ}$

Here, the presence of liang and fen within the same formula reveals that they must have an equivalent function in the text. Since liang is certainly a unit of measurement, this strongly implies the same for fen.

Our readings of such related terms as xian bufan 先餔飯 (strip 8 and tablet 81), xian bushi 先餔食 (strip 76), and houfan 後飯 (tablet 84) depart from those of previous scholars, particularly Yamada Keiji and Zhang Yanchang. These terms, particularly houfan, have been subject to different interpretations by commentators such as Wang Bing 王冰 and Yang Shangshan 楊上善 since the Tang dynasty (618-907 C.E.).

40. Zhang Defang 張德芳, Dunhuang Maquanwan Hanjian jish $i$ 敦煌馬圈灣漢簡集釋 (Lanzhou: Gansu wenhua, 2013), 522 (strip 563B). 
Akahori and Yamada, for example, interpret xian bufan 先餔飯 as 先に 飯を餔 or “first eat food" [before taking medicine]. ${ }^{41}$ In this regard, their interpretation is at odds with Harper's understanding of the phrase as it appears in the Wushier bingfang.42 Their reasoning has to do with a passage from the Warring States corpus, where the adverb xian 先 precedes a verb, as in the following passage from the Han Feizi 韓非子:

\section{仲尼先飯㯟而後啗桃。}

Confucius first ate broomcorn millet and afterwards ate peaches. ${ }^{43}$

Here, Akahori and Yamada infer that xian should be interpreted in a similar fashion in the Wuwei manuscripts; this is based on their assumption that bufan 餔飯 represents a verb-object construction and that xian means "first" when it precedes a verb. They furthermore read xian bushi 先餔食 (strip 76 and tablet $82 \mathrm{~A}$ ) as equivalent to xian bufan. Somewhat puzzlingly, Akahori and Yamada also interpret houfan 後飯 to mean "before eating," even though hou is the antonym of xian. This interpretation owes much to Wang Bing's commentary on the Suwen 素問, where Wang argued that houfan means "before eating." 44 (Here, Wang Bing's view directly contradicts that of Yang Shangshan.)

Yet the reading of xian bufan and houfan proposed by Akahori and Yamada is not the best one. Bushi means supper in contemporary works. The chapter on rites and music in the Baihu tong 白虎通 (compiled first century C.E.), for example, describes bushi as the "meal taken at the start of the shaoyin 少陰 period." 45 The Baihu tong furthermore contrasts bushi with the meals consumed at different times of the day: for example, at the start of the shaoyang 少陽, taiyang 太陽, and taiyin 太陰 periods. Indeed, we find a related usage of the term $b u$ in tablet 83: "Swallow seven pellets at dawn. At suppertime swallow nine pellets. At dusk, swallow 11 pellets" (旦吞七丸, 餔吞九丸, 莫吞十一丸). Furthermore, in other classical works, xian can be understood as "prior to" (xian yu 先 於), as in the following passage from the Zuozhuan 左傳: “Prior to the battle, [Ziyu 子玉] dreamt of a river spirit telling him, 'Give me. Bestow

41. Akahori and Yamada, Shinhatsugen Chügoku kagakushi shiryō no kenkyū, 368, n. 28.

42. Harper, Early Chinese Medical Literature, 228, n. 4.

43. Han Feizi jijie 韓非子集解, ed. Wang Xianshen 王先慎 and Zhong Zhe 鐘哲 (Beijing: Zhonghua, 1998), "Waichu shuo" 外儲說, 299.

44. Chongguang buzhu Huangdi neijing suwen 重廣補注黃帝內經素問, ed. Wang Bing 王冰 and Gao Baoheng 高保衡 (Beijing: Zhongyi guji, 2003), 11/84.

45. Ban $\mathrm{Gu}$ 班固 comp., Baihu tong shuzheng 白虎通疏證, ed. Chen Li 陳立 and Wu Zeyu 吳則虞 (Beijing: Zhonghua, 1994), 3/118. 
upon me the banks of Mei.'" (先战, 梦河神谓己日：界余, 余赐女孟诸 之糜 (涺) $) .4^{6}$

Because of the aforementioned principle of consistency, our reading of xian bushi has ramifications for how we interpret xian bufan. Like Akahori and Yamada, we believe that xian bushi and xian bufan, because of their closeness in form and meaning, should be interpreted similarly (the Shuowen 說文 glosses fan as shi 食). ${ }^{47}$ Since we are reading xian bushi as meaning "prior to supper," it also makes sense to interpret xian bufan as "prior to supper." Our reading, finally, receives support from Zhang Yanchang, who also treats bushi and bufan as equivalents, as referring to supper (a meal taken later in the day). $4^{8}$

Our understanding of xian bufan, finally, has implications for our interpretation of houfan. Pace Akahori and Yamada, we assume that the collection of formulas maintained a minimal level of consistency. If xian is used consistently to mean "prior to," this implies that its antonym hou 後 must refer to "after."

武威漢代醫簡簡介與翻譯

楊勇與董慕達

摘要

1972 年，甘肅武威農民發現了一座無名墓葬，于此墓中出土的醫簡包含 大量的病方以及部分針炎術。本文簡要介紹了这些醫簡的内容，并首次 將之譯成英文。

Keywords: Wuwei, medical strips, pharmacology, Eastern Han dynasty, 武威, 醫簡, 藥物學, 東漢,

46. Chunqiu Zuozhuan zhu 春秋左傳注, ed. Yang Bojun 楊伯峻 (Beijing: Zhonghua, 1990), 467.

47. Xu Shen 許慎, Shuowen jiezi 說文解字 (Beijing: Zhonghua, 1963), 5/107.

48. Zhang Yanchang, Wuwei Handai yijian zhujie, 114, n. 4. 


\section{TRANSLATION}

\section{First Category of Strips}

\section{Strips 1-2}

Blank strips. ${ }^{1}$

Strips 3-5

○治久欬上氣, 喉中如百虫鳴狀, 世歲 2 以上方 : 茈胡 3 、桔梗、蜀椒各 二分，桂、烏 3

喙4、薑各一分。凡六物冶合和, 丸以白密, 大如婴桃。書夜含三丸, 消 4 咽其汁，甚良。5

A formula to treat those over thirty years of age who have a persistent cough, qi rising, and something in the throat that sounds like the crying of a hundred insects [wheezing?]:

Two fen 5 each of Hare's ear root [Bupleurum falcatum or Bupleurum scorzoneraefolium]; root of balloon flower [Platycodon grandiflorum]; and Szechuan pepper [Zanthoxylum simulans or Zanthoxylum bungeanum].

One fen each of cassia twigs [Cinnamomum cassia]; rhizome of Chinese or Szechuan aconite [Aconitum chinense or Aconitum carmichaelii]; and ginger root [Zingiber officinale].

1. The Wuwei editors placed these blank strips at the beginning of the collection, believing that they belonged together.

2. According to He Shuangquan, the Wuwei editors transcribed this character incorrectly. On this point, see He Shuangquan, "Wuwei Handai yijian shiwen buzheng," 39 [hereafter He Shuangquan].

3. Cihu 茈胡 is a variant of chaihu 柴胡; cf. Akahori and Yamada, Shinhatsugen Chügoku kagakushi shiryō no kenkyū [hereafter Akahori and Yamada], 365, n. 5; Zhang Yanchang, Wuwei Handai yijian zhujie [hereafter Zhang Yanchang], 113, n. 4.

4. Akahori and Yamada (366) treat wuhui 烏㻭 as a reference to wutou 烏頭.

5. For the meaning of fen, see Introduction. Although we argue that fen is a weight measure, we do not provide a metric value, since we have yet to find direct evidence that fen was equal to one-quarter liang, as in later periods. On this point, see Nathan Sivin, Chinese Alchemy: Preliminary Studies (Cambridge, MA: Harvard University Press, 1968), 253. For a similar point, see Qiu et al., Zhongguo kexue jishu shi, 338. 
Pulverize ${ }^{6}$ combine, and mix all six of these substances. With white honey, make into pellets the size of cherries. Hold three pellets in the mouth in a twenty-four hour period. Swallow the resulting juice little by little. Extremely efficacious.

\section{Strips 6-7}

治傷寒遂7風方 : 付子 8 三分, 蜀椒三分, 澤舄9五分, 烏喙三分, 細辛五 分，菻五分。凡五物皆冶 6

合，方寸七酒飲，日三飲。7

A formula to treat Cold Damage Disorders and to expel wind:

Szechuan aconite root [Aconitum carmichaelii], 3 fen.

Szechuan pepper, 3 fen.

Water Plantain [Alisma plantago-aquatica], 5 fen.

Rhizome of Chinese or Szechuan aconite, 3 fen.

Chinese wild ginger [Asarum heterotropoides or Asarum sieboldii], 5 fen.

Shu [or Tsangshu or Zedoary; Atractylodes macrocephala, Atractylodes chinensis, A. japonica, A. lancea, Curcuma zedoaria], 5 fen.

6. Harper (Early Chinese Medical Literature, 108) renders ye 冶 as "to smith," in order to preserve the metallurgical connotations. Yet the early pharmacological use of ye did not always entail the use of heat to pulverize or pestle substances, something recently pointed out by Liu Xinglong et al. in "Chengdu Laoguanshan Hanmu chutu yijian 'Liushi bingfang' fangji jixing kaobian," 10 . As they note, ye means crushing to pieces (fensui 粉碎). Their view is seconded by Akahori and Yamada (366), as well as Duan Zhen 段禎, “Jianbo yishu 'ye' zikao”簡帛醫書 “冶”字考, Gansu zhongyi xueyuan xuebao 甘肅中醫學院學報 2009.12，52-54. Duan notes that the exact meaning of ye varies between manuscripts. For this reason, we have chosen to translate ye in a more general sense of "pulverize," leaving open the precise method of rendering pharmacological substances into fine pieces or powder.

7. The Wuwei editors (Wuwei Handai yijian [hereafter Wuwei]), 1; Akahori and Yamada (366, n. 7) and Zhang Yanchang (113) transcribe the character as sui 遂, but treat it as an error for $z h u$ 逐.

8. Fuzi 付 is a variant of fuzi 附子; cf. Akahori and Yamada $(366, n$. 18) and Zhang Yanchang $(114, \mathrm{n} .1)$.

9. Zexi 澤舄 is a variant of zexie 澤瀉; cf. Wuwei editors (1), Akahori and Yamada (366, n. 20), and Zhang Yanchang (114, n. 2). 
Pulverize and combine these six ${ }^{10}$ substances. Take one square-inch spoonful $(2.76 \mathrm{ml})^{11}$ of the mixture and drink three times daily with wine.

\section{Strips 8-10}

治鷹韾 ${ }^{12} \square \square \square$ 言方 : 术、方風13、細辛、薑、桂、付子、蜀椒、桔梗， 凡八物, 各二兩, 并冶合和, 以方寸七, 先餔飯, 米 8

麻飲藥耳。 ${ }^{14} ・$ 治諸症 ${ }^{15}$ : 石症出石, 血症出血, 膏症出膏, 汨症出沺 ${ }^{16}$, 此五疼皆同樂 ${ }^{17}$ 治之。茂、薑、9

矍麦各六分, 兔系 ${ }^{18}$ 實、滑石各七分, 桂半分, 凡六物皆冶合, 以方寸 七酒飲, 日六七。病立愈, 石即出。10

A formula to treat an ailment, causing one to honk like ... [3 illegible characters and one untranslatable character] ... geese (?):

Two liang [27.6 g] each of these eight substances: Shu [Tsangshu or Zedoary]; Fangfeng [Ledebouriella seseloides or Saposhnikovia divaricata]; Chinese wild ginger; ginger; Cassia twigs; Szechuan aconite root; Szechuan pepper; balloon flower.

10. The text specifies five, but this is an obvious (and not unusual) error.

11. On the square-inch spoon, one of several ancient measures for drugs, see Zhao Youchen 趙有臣, “Fangcunbi kao 方寸七考,” Jiangsu Zhongyi 江蘇中醫 7 (1961), 2. According to Zhang Yanchang (114, n. 6), this should be worth $2.74 \mathrm{ml}$.

12. Akahori and Yamada (367) transcribe this as sheng 聲. The graph on the photograph is too unclear to verify that this is in fact the case.

13. Fangfeng 方風 is a variant of fangfeng 防風; cf. Wuwei editors (2), Akahori and Yamada $(367$, n. 26), and Zhang Yanchang (114, n. 2).

14. The meaning of $\mathrm{er}$ 耳 is unclear.

15. For interpreting long 疼 as a variant of long 症 (retention), see Wang Pan 王盼 and Cheng Panji 程磐基, “Wuwei Handai yijian 'long' 'ganlong' 'wulong' tantao" 武威 漢代醫簡 “疼” “泔疼” “五症” 探討, Zhongyi wenxian zazhi 中醫文獻雜志 2009.5, 8-10.

16. Akahori and Yamada (367) and the Wuwei editors (2) have interpreted this character as gan 泔. We concur with Sivin (Personal Correspondence) that this character was actually written as $g u$ 汨, but was a possible error for gan. According to Baxter (Personal Correspondence), there was no phonetic connection. Still, we agree with the interpretation of the Wuwei editors, who interpret this as a reference to an illness leaving a milky debris.

17. Wuwei (2), Akahori and Yamada (368, n. 35), and Zhang Yanchang $(115$, n. 2$)$ all treat yue 樂 as a variant of yao 藥.

18. Tusi 兔系 is a variant of tusi 菟系; cf. Akahori and Yamada (368); Zhang Yanchang $(115$, n. 3). 
Pulverize, combine, and mix all of these ingredients. Before supper, drink a square-inch spoonful [2.76 ml] of the medicine with millet porridge.

Formula for treating the various forms of retention: for stone retention, it expels stones; for blood retention, it expels blood, for grease retention, it expels grease, and for gan retention, it expels gan. All of these five ${ }^{19}$ forms of retention are treated with the same medicine:

Six fen each of Shu [or Tsangshu or Zedoary]; ginger; and Pink [Dianthus superbus or D. chinensis].

Seven fen each of the seeds of Dodder [Cuscuta japonica or C. chinensis] and Talc (soapstone).

One-half fen of Cassia twigs.

Pulverize and combine all six of these substances. With alcohol, take a square-inch spoonful $[2.76 \mathrm{ml}]$ six or seven times a day. The illness will immediately be cured, and the stones will come out right away.

\section{Strips 11-12}

口（病方：乾當歸二分，弓窮 20 二分，牡丹二分，漏盧 ${ }^{21}$ 二分，桂二分，蜀 椒一分，䖟 ${ }^{22}$ 一分，凡 $11^{23}$

19. The text only mentions four forms of retention. This is either a counting error or the scribe neglected to copy the fifth form of retention; on this point, see Akahori and Yamada (368, n. 34).

20. According to Akahori and Yamada (369, n. 44) and Zhang Yanchang (116), gongqiong 弓穹 is a variant of xiongqiong 芎谢.

21. We render loulu 漏盧 as Rhaponticum [Rhaponticum uniflorum], but Akahori and Yamada $(369$, n. 46$)$ are uncertain about the meaning of this term in ancient times.

22. Some doubts exist as to the translation of meng 䖟. The Wuwei editors (2) gloss meng as beimu 貝母 [Szechuan fritillary or Fritillaria cirrhosa]. Akahori and Yamada (369, n. 47) acknowledge the plausibility of this explanation, based on Qing commentaries and the curative powers associated with beimu. We know that beimu appears in the Bencao jing jizhu, as well as in the Dunhuang manuscripts; for the latter, see Barrett, "Appendix 1," 369. However, we should note that feimeng 蜚虬 (gadfly) has similar curative properties as beimu in the Bencao jing jizhu, insofar as it also purportedly controls blood stasis. Taking meng as short for feimeng has the advantage of allowing us to read the original text more literally. For feimeng and beimu, see Bencao jing jizhu, 3/118.

23. Although previous scholars regard strips 11 and 12 as part of the same formula, we concur with Liu Jinhua 劉金華 that the contents of the strips are unrelated and should be treated separately. On this point, see Liu Jinhua, "Wuwei Handai yijian jiaodu wuze" 武威漢代醫簡校讀五則, Nanjing zhongyiyao daxue xuebao (shehui kexue ban) 南京中醫藥大學學報 (社會科學版) 4.4 (December 2003), 234 . 
$\square^{24} \square \square$ 皆冶合, 以淳酒25和, 飲一方寸七, 日三飲。倍恿 ${ }^{26}$ 者臥藥 $[\text { 中 }]^{27}$, 當出血 ${ }^{28}$ 。久瘀 $29 \circ 12$

[2 illegible characters] A formula for stasis:

Dried Chinese angelica [Angelica sinensis], 2 fen.

Szechuan lovage [Ligusticum wallichii], 2 fen.

Tree Peony or Moutan [Paeonia suffruticosa], 2 fen.

Rhaponticum [Rhaponticum uniflorum], 2 fen.

Cassia twigs, 2 fen.

Szechuan pepper, 1 fen.

Gadfly (?), 1 fen.

[Indeterminate number of missing characters and 2 illegible characters]. Pulverize and combine all of these ingredients. Drink one square-inch spoonful $(2.76 \mathrm{ml})$ mixed with a fine strongly-flavored alcohol, three times a day. For those with back pain (?), sleep in the

24. The Wuwei editors only mark two illegible graphs, even though there was room for more text on the strip.

25. Chunjiu 淳酒 is a variant of chunjiu 醇酒, or a fine alcohol with a strong flavor.

26. The Wuwei editors (2) suspect bei 倍 should be understood as bei 背 (back). This reading is plausible based on the context of the formula, which calls for the afflicted to lie in the medicine, as well as the fact that bei 倍 (Schuessler $4-61<\mathrm{LH}{ }^{*} \mathrm{~b} \partial^{\mathrm{B}}$; ${ }^{*} \mathrm{~b} ə^{\mathrm{c}}$ ) can be a phonetic loan for bei 背 (Schuessler $5-32<\mathrm{LH}^{*} \mathrm{p}^{\mathrm{c}}$ ). Baxter (Personal Correspondence) confirmed that these two characters, which did not have identical pronunciations, could be used as phonetic loans for each other.

This reading has also been adopted by Akahori and Yamada (369-70). He Shuangquan (39), however, demurs. He argues that the Wuwei editors transcribed the character incorrectly. The character is 停, which is a graphic variant of $y i$ 倚 (Schuessler $18-1<\mathrm{LH}$ ${ }^{*}$ ?iai ${ }^{\mathrm{B}}$ ) and which He Shuangquan claims is a phonetic loan for $j i$ 畸 (regular, standard). Thus, he takes yiyong 倚恿 to mean "extreme or unusual pain." While Schuessler does not provide a reconstruction for $j i$, there should be no problem with He Shuangquan's claim; in general, when two characters had the same phonetic element in the Han dynasty, they had similar pronounciations.

Yong 急 is a variant of tong 痛. This fact was too obvious to the Wuwei editors to remark upon.

27. The picture is not entirely clear, but we have determined based on the shape of the graph that the character is zhong 中.

28. We are also punctuating the text differently from Akahori and Yamada (369). We cannot make sense of their reading.

29. We cannot verify this graph from the photographs of the strips. 
medicinal remedy and [the static] blood will come out. In cases of long-term stasis ...30

\section{Strip 13}

治金創 ${ }^{1}$ 止急, 令創中溫方：曾青 ${ }^{2}$ 一分, 長石 ${ }^{33}$ 二分, 凡二物皆冶合 和，溫酒飲一刀，日三，創立不慈。13

A formula to treat a metal wound, to stop the pain, or to warm the area inside the wound:

Malachite or Laminar, I fen.

Sulfate mineral anhydrite, 2 fen.

Pulverize, combine, and mix both of these substances. With warm alcohol, drink one knifeful ${ }^{34}[0.276 \mathrm{ml}]$ three times a day. The wound will immediately cease to hurt.

\section{Strips 14-15}

皆冶合和, 以方寸七酒飲, 不過 35 , 再飲。血立出, 不不 36 即大便血。 良，禁。・治金創腸出方：冶龍骨 14

30. It is unclear why the text ends here, since we would expect there to be more content.

31. Jinchuang 金創 is a variant of jinchuang 金瘡. In this, we follow the Wuwei editors (3).

32. Akahori and Yamada (370, n. 51) gloss cengqing 曾青 as kongqueshi 孔雀石; for the translation of the term, see Sivin (290).

33. This is also called fangshi 方石. Zhang Yanchang (116,n. 3) explains this ingredient as an ore of a sulfate mineral anhydrite.

34. Yi dao 一刀 must mean yi dao gui一刀圭 (one knifeful), with the gui being left out; see Wuwei editors (3). The original text specifies that the portion be equal to one knifeful. One knifeful is described by Zhang Yanchang $(123, n$. 3$)$ as one-tenth of a squareinch spoon.

35. Buguo 不過 is possibly an error for buyu 不愈. According to Baxter (Personal Correspondence), there is no phonetic connection between guo 過 (Schuessler 19-4 $<\mathrm{LH}^{*}$ kuaic; ${ }^{*}$ kuai) and $y u$ 愈 (Schuessler $10-23<\mathrm{LH}^{*}{ }^{*} \mathrm{jo}^{\mathrm{B}}$ ).

Another possible reading, proposed by one of the reviewers, is "do not drink more than twice."

36. Bubu 不不 can be interpreted in different ways. Akahori and Yamada (370, n. 55) argue that the scribe mistakenly transcribed the character twice. This is not the only interpretation, however. We argue that $b u b u$ 不不 should be read together, apart from ji dabian xue 即大便血. In this case, we take it as an error for $b u$ chu 不出. 
三指[撮] ${ }^{37}$, 和以鼓38汁，飲之 $\square \square$ 禁39 $\square \square \square \square \cdot$ 治金創內座 ${ }^{40}$, 創養 ${ }^{41}$ 不急, 腹張方 : 黃芩 $\mathbf{1 5}$

Pulverize, combine, and mix all together. Take one square-inch spoonful and drink with alcohol. If there is no improvement (?), drink another portion and the blood should immediately come out. If it does not, there will be passing of blood in the stool. Efficacious. Proscribed.

A formula for treating metal wounds in which the intestines have spilled out: Pulverize fossil bones, taking a three-finger pinch, mixing it with fermented bean juice and drink [2 illegible characters]... proscribed... [4 illegible characters].

A formula to treat a metal wound with a small internal swelling and for instances where the wound is itchy, does not hurt, and causes abdominal distension:

Baical skullcap [Scutellaria baicalensis] ...

\section{Strip 16}

治目恿方：以春三月上旬治藥。曾青四兩, 载42鹽三兩, 皆冶合, 以乳 汁和, 盛以銅器, 以傅43目, 良。16

37. The picture is not entirely clear, but we have determined based on context that the character is cuo 撮.

38. Wuwei editors (3) and Zhang Yanchang (117) argue that $g u$ 鼓 is an error and should be chi 豉, as there is no phonetic connection (Baxter, Personal Correspondence).

39. Akahori and Yamada (370) write $r u$ 人 before jin 禁; yet the photograph is too unclear to determine which graph appears next.

40. There is disagreement about how the character should be transcribed and interpreted: is it jing 痤 or is it cuo 痤? The Wuwei editors (3) are agnostic about this issue. Zhang Yanchang $(117, n$. 5) maintains that the graph should be interpreted as the latter. The Wuwei editors quote the Shuowen jiezi $(7 / 155)$ and gloss the term as a minor swelling (xiaozhong 小腫). On the basis of received texts from the Tang, Akahori and Yamada $(371, \mathrm{n} .61)$ argue that the character is jing 痤.

41. Yang 養 is a variant of yang 餈; also see Akahori and Yamada (371, n. 62) and Zhang Yanchang (117, n. 6).

42. The Wuwei (3) editors and Zhang Yanchang $(117, n$. 2) regard 载 as a variant of rong 戎. Some questions remain as to what rongyan 戎鹽 refers. The Wuwei editors (3) speculate that rongyan refers to blue-green colored salt. Akahori and Yamada (371, n. 65) suggest that rongyan is salt from the Northwest. Rongyan appears in the Bencao jing jizhu $(4 / 189)$ and is associated with treating eye disorders. For our translation of the substance, see Sivin (280).

43. $F u$ 傅 (Schuessler $1-67<\mathrm{LH}^{*} \mathrm{pua}^{\mathrm{c}}$ ) is a phonetic loan for $f u$ 敷 (Schuessler $1-67$ $\left.<\mathrm{LH}^{*} \mathrm{p}^{\mathrm{h}} \mathrm{ua}\right)$. 
A formula to treat eyes in pain: In the first ten-day period of the three months of spring, make a medicine: four liang [55.2 g] of Malachite or Laminar, and three liang [41.4 g] of Turkestan Salt. Pulverize and combine all of these, mixing together with milk and filling a bronze utensil with it. Use this to apply to the eyes. Efficacious.

\section{Strips 17-18}

治百病膏藥方：蜀椒一升，付子廿果44, 皆父45。豬肪三斤, 煎之五沸, 浚去宰46。有病者取 $17^{47}$

大如羊矢 ${ }^{4}$, 溫酒飲之, 日三四。與 49 宰搗之, 丸大如赤豆。心寒氣, 脅 下急，吞五丸，日三吞。18

A formula for medicinal paste that treats the many illnesses:

Szechuan pepper, I sheng [200 $\mathrm{ml}]$.

Szechuan aconite root, 20 heads $(k e)$

Mince all of these. Fry with three jin [66o g] of pig fat. Boil it five times and strain the liquids to get rid of the sediment. The ill should take a portion as big as a sheep's dung. With warm alcohol, drink it three to four times a day. The sediment should be beaten and made into a pellet as big as a red bean. In cases where the heart ails from cold qi and there is pain on the sides of the chest, swallow five pellets three times a day.

44. Guo 果 is a variant of ke 顆; cf. Wuwei editors (3), Akahori and Yamada (372, n. 67), Zhang Yanchang (118, n. 1). Here, we break with Akahori and Yamada, who treat $k e$ as the equivalent of banliang 半兩.

45. Fu父 is short for fuqie 父且 or fuju咬咀; the scribe must have left out the second character; see Wuwei editors (3), Akahori and Yamada (372, n. 68), and Zhang Yanchang $(118$, n. 2$)$.

46. Zai 宰 is a variant of $z i$ 㳯; cf. Wuwei editors (4), Akahori and Yamada (372, n. 70), and Zhang Yanchang (118, n. 4).

47. According to Liu Jinhua ("Wuwei Handai yijian jiaodu wuze," 234-35), strips 17 and 18 do not belong together. This is a distinct possibility, but not a foregone conclusion.

48. Shi 矢 (Schuessler $26-19<\mathrm{LH}^{*} \mathrm{sis}^{\mathrm{B}}$ ) is a phonetic loan for shi 屎 (Schuessler 26-20 $\left.<\mathrm{LH}^{*} \mathrm{si}^{\mathrm{B}}\right)$.

49. The $y u$ 與 is hard to make sense of. The Wuwei editors (4) propose to treat this as an error for $q i$ 其, as does He Shuangquan (39). There is, however, another possibility, suggested by one of the reviewers, namely, to take $y u$ 與 as a graphic variant or error for $j u$ 擧 (all). 


\title{
Strips 19-25
}

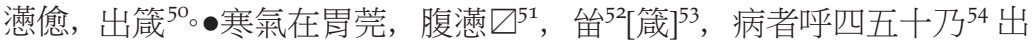 \\ 筬。次刾 5519 \\ 膝下五寸56分間榮 57 , 深三分, 留箴如炊一升米頃, 出箴, 名曰三里。次 \\ 判項從上下十一椎 58 侠椎兩 59 , 刾榮 20
}

50. Akahori and Yamada transcribe zhen 蔵 instead of zhen 筬; we follow here the Wuwei editors (4) and Zhang Yanchang (118) after verifying the photograph of the strip.

51. The Wuwei editors have added a chang 腸 after the second men 㴽 on strip 19; Akahori and Yamada (372) and Zhang Yanchang (118) have followed the editors in their versions. However, the photograph is too unclear for us to be confident in this transcription. Akahori and Yamada (372) transcribe the second half of strip 19 differently from the Wuwei editors, Zhang Yanchang, and us. After the second men, Akahori and Yamada render the line as 腸 $\square$ 勞 $\square$ without supplying a rationale. We are also uncertain whether the material arranged under strip 19 belongs to a single strip; the photograph indicates the existence of a break.

52. The graph 甾 is a variant of liu 留; see Zhang Yanchang (118).

53. The picture is not entirely clear, but we have determined based on the shape of the graph and context that the character is zhen 箴.

54. Akahori and Yamada (372) transcribe ze 則 instead of nai 乃; cf. Wuwei editors (4) and Zhang Yanchang (118). After examining the photograph of the strip, we concluded that the graph is nai.

55. Akahori and Yamada substitute $c i$ 刺 for $c i$ 判; here, we follow the Wuwei editors (4) and Zhang Yanchang (118) after checking the photograph.

56. Akahori and Yamada $(373, \mathrm{n} .77)$ pointed out that the placement of the acupoint in this strip is different from received parallels in Huangfu Mi, Huangdi zhenjiu jiayi jing (xinjiao ben) 黃帝針尒甲乙經(新校本), ed. Huang Longxiang 黃龍祥 (Beijing: Zhongguo zhongyiyao keji chubanshe, 1990), 3/194. There, the needle is to be placed three cun 寸 instead of five cun below the knees. We can potentially reconcile the discrepancies with reference to the different values of cun (namely, between the Eastern Han and the Jin dynasties). According to the Hanyu da cidian, one cun was worth $2.375 \mathrm{~cm}$ in the Eastern Han, whereas it was equivalent to $2.42 \mathrm{~cm}$ in the Jin.

57. The Wuwei editors (4) and Zhang Yanchang (118) have left the character as rong 榮. However, Akahori and Yamada $(373, \mathrm{n}$. 75) interpret rong 榮 as referring to ying 營 (an acupoint). We prefer Zhang's reading since it preserves the original text, which makes sense as is.

58. Cong shangxia shiyi zhui 從上下十一椎 is hard to make sense of. The Wuwei editors have not explained the meaning of shangxia 上下. We believe that the characters have been jumbled and thus read the line as: cong xiang shangxia shiyi zhui 從項上下十 一椎 (from the neck base [xiangshang] down to the eleventh vertebrae). We thus interpret xiangshang as referring to a specific location. This reading is consistent with the translation offered by Akahori and Yamada (374).

59. Based on parallels in the Huangdi zhenjiu jiayi jing, Akahori and Yamada (372, n. 78) argue a character is missing after liang 兩, namely, bang 傍. The meaning of the line does not change much with this addition. 
深四分, 留箴百廿息, 乃出箴, 名曰肺輸。刾後三日病偷平復。・黃帝 治病神魂忌：人生一歲冉条心，21

十日而死 ; 人生二歳60册冬腹, 五日而死 ; 人生三歳冊冬背, 廿日死; 人生四歲61册冬頭, 三日而死; 人生五 22

歲母久足, 六日而死; 人生六歲母条手, 二日死 ; 人生七日母条脛, 世 日而死 ; 人生八歲冉冬肩, 九日而死 ; $23^{62}$

者與五箴同，六十至七十者與六歳同，七十至八十者與七歳同，八十至 九十者與八歳同, 九十至 24

百歲者與九歲同, 年已過百歳者不可条㓬。氣脈壹絕, 条判者隨歲63条死 矣。獨 ${ }^{6} 425$

When the fullness is cured, remove the needle.

If cold qi resides in the gastral cavity and the abdomen is full [indeterminate number of missing characters], leave the needle ... the ill should exhale forty to fifty times before removing the needle. Next, needle the rong five cun $[2.375 \mathrm{~cm}$ ] below the knees to the depth of three $f e n[0.713 \mathrm{~cm}]$, leaving the needle long enough to cook about one sheng $[200 \mathrm{ml}]^{65}$ of rice before removing it. The name of this acupoint is "three $l i . "$

Next, needle the area that reaches from the neck base [xiangshang] down to the eleventh vertebrae: [there], needle the rong that press both sides of the vertebrae to the depth of four fen $[.95 \mathrm{~cm}]$, leaving the needle long enough for [the ill] to breathe one hundred twenty times before removing it. The name of this [acupoint] is called "Feishu" (lung

6o. The graph sui 歲 is a variant of sui 歲.

61. The graph sui 歲 is a variant of sui 歲.

62. There appears to be a missing strip after 23 .

63. Based on context, we are interpreting the graph 歳, elsewhere a variant of sui 歲, as another variant of zhen 筬.

64. According to the Wuwei editors (4) and Akahori and Yamada (374, n. 82), the strip is missing some contents.

65. Akahori and Yamada translate the line as yi dou mi一斗米 instead of yi sheng $m i$ 一升米. They offer no explanation for this substitution, though writing sheng 升 in place of dou 斗 was common in early excavated materials. The Wuwei editors (4) and Zhang Yanchang (118), in contrast, read the line as it appears. We follow the editors and Zhang Yanchang for the following reasons. The current metric values of sheng and dou are approximately $200 \mathrm{ml}$ and $2000 \mathrm{ml}$ respectively. One sheng of rice is slightly more than the standard rice cooker cup (a full American cup is $240 \mathrm{ml}$ ). On a stovetop, one cup of rice requires less than 20 minutes of cooking time (brown rice about 30 minutes), roughly the period of time that an acupuncture needle is nowadays left at a site. If the graph in question is indeed an error for dou, that would imply that the acupuncture needle was left in place for hours. 
transporter). Three days after the needling, the afflicted will be cured and will return to normal.

According to the Taboos of the Yellow Emperor for Treating Ills and [Protecting] the Spirit and Hun [Soul] (?): When a person is a year old, the heart system is not to be cauterized; otherwise, he or she will die within 10 days. When a person is two years of age, the abdomen is not to be cauterized; otherwise, he or she will die in 5 days. When a person is three years of age, the back is not to be cauterized; otherwise, he or she will die in 20 days. When a person is four years of age, do not cauterize the head; otherwise, he or she will die within 3 days. When a person is five years of age, do not cauterize the feet; otherwise, he or she will die within 6 days. When a person is six years of age, do not cauterize the hands, otherwise he or she will die within 2 days. When a person is seven years of age ${ }^{66}$ do not cauterize him or her in the shins; otherwise, he or she will die in 30 days. When a person is eight years of age, do not cauterize the shoulders; otherwise, he or she will die in 9 days. Now, a person ... [missing strip] ...

... is like someone of five years of age. A person between sixty and seventy is like someone six years of age. A person between seventy and eighty is like someone who is seven years of age. A person between eighty and ninety is like someone eight years of age. A person between ninety and one hundred is like someone nine years of age. A person over one hundred years of age cannot receive cauterizing or needling, because the $q i$ vessels have been entirely cut off. Those who have been cauterized or needled will die soon after the needling or cauterizing. Only $\ldots{ }^{67}$

\section{Strip 26}

身不創者, 名曰 $\square \square \square \square$, 扁雍種, 上下左右轉 $\square \mathbf{2 6}^{68}$

66. The text reads seven days, but this is undoubtedly an error for seven years. Akahori and Yamada (374, n. 81) and Zhang Yanchang (119) also treat the $r i$ 日 in ren sheng qi ri 人生七日 as an error. The ri should be sui 歲 (years).

67. For a previous discussion of these prohibitions in the Wuwei manuscripts, see Donald Harper, "Dunhuang Iatromantic Manuscripts," in Vivienne Lo and Christopher Cullen, Medieval Chinese Medicine; The Dunhuang Medical Manuscripts (London and New York: RoutledgeCurzon, 2005), 134-64; 151-53.

68. The Wuwei editors (6) do not write chuang 創; cf. Akahori and Yamada (375) and Zhang Yanchang (120). In our view, the character, a graphic variant of chuang 瘡, is clear. But the graphs for zhe 者 and ming 名 are unclear.

Akahori and Yamada (375) transcribe the end of the line differently, replacing the zhuan 轉 with another character and adding 軧. The Wuwei editors (6) do not transcribe any character where Akahori and Yamada write zhuan, leaving only a single blank spot. Our determination of the character is based on the photograph and the 
[Indeterminate number of missing characters] $\ldots$ in cases where the ill does not have a skin wound. The name is [4 illegible characters] ... swelling all over the body, and the upper and lower, as well as the right and left turn ... [ 1 illegible character]

\section{Strip 27}

】者, 名曰泉 69 水也。先從 $\square$ 氣逆, 膝以下寒, 氣脈不通, 先 $27^{70}$

[Indeterminate number of missing characters and one untranslatable character] it is referred to as "Spring Waters." It first follows [indeterminate number of missing characters] ... reversal of $q i$, causing cold below the knees and interruption in the $q i$ vessels. First ...

\section{Strip 28}

\section{$\square \square$ 出口飲食已驗 $\square \mathbf{2 8}^{7^{11}}$}

\section{[Contents too fragmentary to translate]}

\section{Strip 29}

$\triangle[\text { 石 }]^{72}$ 鐘乳三分, 巴豆一分，二者 73 二分，凡三物皆冶合，丸以蜜，大 如吾實。宿冊食, 旦吞三丸。29

larger context, though the right side of the character is too unclear for us to determine this with certainty. This is also the opinion of He Shuangquan (39).

Yongzhong 雍種 is a variant of yongzhong 臃腫 (swelling). Also see Akahori and Yamada (375, n. 85) and Zhang Yanchang (121, n. 1). Zhang Yanchang (121) argues that bian 扁 (Schuessler 23-27< *LH penc) is a phonetic loan for bian 遍 (Schuessler 23-27 $<\mathrm{LH}^{*}$ penc).

69. There is disagreement about the graph before shui 水. Akahori and Yamada (375, n. 87) write bai 白 for the first character and interpret baishui 白水 as a reference to an illness, based on the Zhubing yuanhou lun jiaoshi 諸病源候論校釋, ed. Nanjing zhongyi xueyuan 南京中醫學院 (Beijing: Renmin weisheng chubanshe, 1980), 21/482. However, the Wuwei editors (6) take the graph before shui to be quan 泉; quanshui 泉水 is also the name of an acupoint. He Shuangquan argues that the same character is qiong 窮. The photograph of the character suggests that the graph is actually quan 泉.

70. For strip 27, the strip is broken after the character cong 從, so it is unclear whether the contents now transcribed as part of one strip actually belonged together. Akahori and Yamada $(375, n$. 86) suspect that the contents were not originally part of the same strip.

71. The yin 飲 is not clear from the photograph. The Wuwei editors (6) and Zhang Yanchang (120) transcribe the characters as yinshi 飲食, an attested usage throughout the Neijing corpus. Akahori and Yamada (375) render the characters, however, as yinyin 飲飲.

72. The picture is not entirely clear, but we have determined based on the shape of the graph and context, that the character is shi 石. The Wuwei editors (6), Akahori and Yamada (375), and Zhang Yanchang (120) all transcribe the graph as shi.

73. The meaning of erzhe 二者 is unclear. The context of the passage suggests that there should be another name of a medicinal substance, but erzhe is unattested in the 
[Indeterminate number of missing characters and one untranslatable character] ...

Stalactite, 3 fen.

Croton [Croton tiglium], one fen.

Erzhe [i.e., an unknown substance], 2 fen.

Pulverize and combine all of these three substances. With honey, make into a pellet as big as the seed of a parasol tree. Do not eat at night. Swallow three pellets at dawn.

\section{Strip 30}

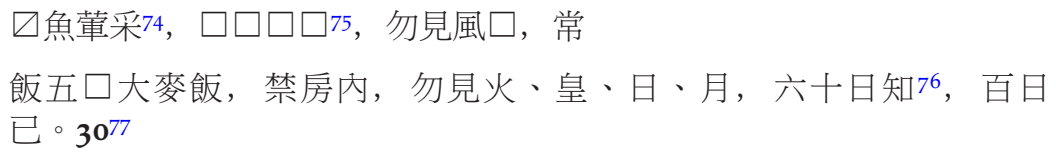

literature. We suspect that this is a copier error. Yuan Renzhi 袁仁智, however, speculates that erzhe is an error for daizhe 代赫 (Hematite). On this point, see Yuan Renzhi 袁 仁智, “Wuwei Handai yijian jiaozhu shiyi” 武威漢代醫簡校注拾遺, Zhongyi yanjiu 中醫 研究 24.6 (2011), 78-79; 78 .

74. The graph cai 采 is a variant of cai 菜; cf. Wuwei editors (6); Zhang Yanchang (121, n. 5).

75. The Wuwei editors (6) mark $\square$ in place of the four blank squares we have left for illegible characters, as do Akahori and Yamada (376) and Zhang Yanchang (120).

76. We take $z h i$ 知 to mean "to improve"; see Zhang Yanchang (121).

77. Transcriptions vary. Zhang Yanchang's transcription departs from that of the Wuwei editors and Akahori and Yamada insofar as he adds four characters after cai 菜 (he does not explain where he found the additional characters): juren guiyi 舉任歸醫. In addition, he adds $y i$ 倚 (which we cannot see based on the photograph), whereas the Wuwei editors and Akahori and Yamada leave a blank for missing text. He finally adds a cha 茶 after the wu 五 so that the line reads: yi chang fan wucha damai fan 倚常飯五茶大 麥飯. This appears to have been guesswork on his part, and we cannot verify this transcription based on the photographs.

He Shuangquan transcribes the line differently: 禁用魚莗菜。擇良醫。勿見風。食 常飯五茶大麥飯。He added jinyong 禁用 and ze liang yi 擇良醫, which we cannot verify from the photographs. We also cannot verify the graphs for shi 食 and cha 茶.

Akahori and Yamada added a rou 肉 in front of yu 魚. Huang 皇 has been interpreted differently by scholars. The Wuwei editors (6) and Akahori and Yamada (376) regard huang as an error for xing 星. He Shuangquan (39) takes huang 皇 (Schuessler 3-24<LH * yuan) as a phonetic loan for huang 煌 (Schuessler 3-24< LH * yuan).

There are also questions about huang 皇. Zhang Yanchang (121) reads huohuang 火皇 or huoxing 火星 as a binome. Akahori and Yamada, however, read huo 火 and huang 皇 as referring to two separate entities. We follow Akahori and Yamada here, since the sentence seems to have been structured around four single characters. We should point out that parallels in the Wushier bingfang support our reading. On this point, see Qiu Xigui, ed., Changsha Mawangdui Hanmu jianbo jicheng, vol. 5, 273 (329-19). 
[Indeterminate number of missing characters] ... Fish and pungent vegetables ... [4 illegible characters]. Do not be exposed to wind ... [ 1 illegible character] ... One can regularly eat five [ 1 illegible character] ... a meal of barley, but sexual relations are interdicted. Do not be exposed to fire, stars, sun, or moon. In sixty days, you will improve, and in one hundred days, the illness will end.

\section{Strip 31}

】兩手不到頭，不得臥方：大黃、匀樂78、薑、桂、桔梗、蜀 31

[Indeterminate number of missing characters] ... A formula for cases where the two hands cannot reach the head and one is unable to sleep:

Rhubarb [Rheum spp.]; Peony [Paeonia lactiflora]; ginger; cassia twigs; root of balloon flower; and Szechuan ...

\section{Strip 32}

】飲水, 常作赤豆麻洙79服之, 世日止。禁豬月80、魚、莗采。32

[Indeterminate number of missing characters] ... drink water and regularly prepare a porridge of adzuki beans, taking it for 30 days before stopping. One is interdicted from eating pork, fish, and pungent vegetables.

\section{Strip 33}

口日病愈。禁酒、莗采、魚、亲 ${ }^{81}$ 。3 3

[Indeterminate number of missing characters] days. The illness will be cured. One is interdicted from alcohol, pungent vegetables, fish, and spicy foodstuffs.

78. Shaoyue 勺樂 is a variant of shaoyao 药藥.

79. Zhang Yanchang (121) reads chidou mazhu 赤豆麻洙 as chidou mimo 赤豆糜沫.

80. Yue 月 should be understood here as rou 肉, as the two graphs were often undifferentiated in ancient manuscripts. The Wuwei editors (6) transcribe the character as rou 肉 here and below.

81. Qin 亲 is a variant of xin 辛; cf. Wuwei editors (6); Akahori and Yamada (377, n. 100); Zhang Yanchang (121). Whereas the Wuwei editors and Zhang Yanchang read xin as part of a binome (yuxin 魚辛), we follow the translation of Akahori and Yamada, which treats $y u$ and $x i n$ as two separate words. Xin 辛 here would refer to spicy foodstuffs. 


\section{Strip 34}

$\square$ 鬲 ${ }^{82}$ 上當歐 83 , 在鬲下當下泄。良。禁, 勿忘 84 傳也。34

[Indeterminate number of missing characters] ... [in cases where the illness resides] above the diaphragm, it is fitting to purge through vomiting. [In cases where the illness resides] below the diaphragm, it is fitting to purge by [inducing] diarrhea. Efficacious. Proscribed. Do not wantonly transmit this formula.

\section{Strip 35}

$\square$ 七。當大下，水盡，飲大麥粥 $\square \square \square^{85} 35$

[Indeterminate number of missing characters] ... seven. There will then be diarrhea. Once the diarrhea stops, drink a portion of barley porridge. [3 illegible characters.]

\section{Strip 36}

\section{五分 $\square[\text { 五 }]^{86} \square$ 物皆 $\square$ 酒飲一方寸七, 日三飲。不過三飲, 此藥禁。 ${ }^{87} 36$}

82. Ge 鬲 is a variant of $g e$ 膈; cf. Zhang Yanchang (121, n. 10).

83. Wuwei editors (6), Akahori and Yamada (377, n. 102), and Zhang Yanchang (121) were unsure about the transcription of the two characters dang ou 當歐. However, the photographs are clear to us. $\mathrm{Ou}$ 歐 is a variant of ou 嘔; cf. Wuwei editors (6), Zhang Yanchang (121), and Akahori and Yamada (377, n. 102).

84. Wang 忘 is a variant of wang 妄; cf. Wuwei editors (6), Akahori and Yamada (377, n. 103), and Zhang Yanchang (121, n. 11).

85 . Some disagreement exists with respect to the transcription. In contrast to the Wuwei editors and Akahori and Yamada, Zhang Yanchang (121) transcribes the lines as follows: $\square \square$ 當吞七。當大下。水盡。飲大麥粥。

Zhang does not explain why he transcribes the strip differently from the Wuwei editors, and the current photograph of the strip does not support his interpretation of its contents.

86. The picture is not entirely clear, but we have determined based on the shape of the graph and context that the character is wu 五.

87. The transcriptions provided by Akahori and Yamada (377) and He Shuangquan depart from those of the Wuwei editors (6) and Zhang Yanchang (121). For example, the Wuwei editors and Zhang Yanchang do not transcribe the second wu 五; cf. Wuwei editors (6) and Zhang Yanchang (120). Akahori and Yamada (377), however, do. Akahori and Yamada $(378, n$. 104) note that they are unsure about whether the contents belonged to a single strip, since the strip is broken before $w u$ 物 and again after jie 皆. The term jin 禁 is ambiguous here. It could refer to the fact that the formula should not be transmitted to the uninitiated, or it could mean that the medicine should not be administered with particular foods, drinks, or activities. 
5 fen [ 1 illegible character] five [indeterminate number of missing characters]

All of these substances ... [indeterminate number of missing characters] with alcohol, drink one-square inch spoonful [2.76 ml] three times a day. Do not drink more than three times. ${ }^{88}$ This medicine is interdicted.

Strip 37

胡四 $\square 37$

[untranslatable]

Strip 38

口藥畢餘炊之 38

[Not enough context to provide a translation]

Strip 39

$\square 39$

[untranslatable]

Strip 40

$\triangle 40$

[untranslatable]

Strip 41

$\triangle 41$

[untranslatable]

88. This is not the only possible reading of the sentence. It is also possible to punctuate the sentence differently: 不過, 三飲. The line would then read, "If insufficient, drink three more times." 


\section{Second set of strips}

\section{Strips $42-43$}

- 治魯氏青 89 行解 ${ }^{90}=$ (解) 腹 ${ }^{1}$ 方 : 麻黃业分, 大黃十五分, 厚朴、石 膏、苦參各六分, 烏喙、付子各二分, 凡七物42

皆 $\square \square \square \square \square 92$ 方寸七一飲之，良甚。皆愈。93傷寒逐風。9443

Mr. Lu's green-powder formula to treat [illnesses] by producing sweat and emptying the abdomen:

Ma-Huang [Ephedra sinica or E. equisetina], 30 fen.

Rhubarb, 15 fen.

89. According to Du Yong 杜勇, Lu Shi 魯氏 refers to a person. Qing 青 refers to a green colored powder; see Du Yong 杜勇, “Wuwei Handai yijian 42, 43 jian kaoshi," 武 威漢代醫簡 42、43簡考釋, Gansu zhongyi 甘肅中醫 11.5 (1998), 7-8. This is, however, not the only possible translation. The title of the formula could be rendered (more literally) as: "A formula to treat Mr. Lu's green, to combat illness by producing sweat, and to empty the abdomen."

90. Scholars have explained xingjie 行解 differently. Quoting Wang Hui 王輝, Zhang Yanchang $(122, n .2)$ glosses the term as "draining internal heat, cold, poison, or perversity through strolling." Our reading, however, draws upon the Qianjin yaofang 千金要 方, ed. Liu Qingguo 劉清國 (Beijing: Zhongguo zhongyiyao chubanshe, 1998), 9/168, where xingjie is explained as treating a range of illnesses through activities producing sweat. For Wang Hui 王輝, see “Wuwei Handai yijian yinan ciyu qiuyi," 武威漢代醫簡 疑難詞語求義, Zhonghua yishi zazhi 中華醫史雜志 1998.2, 122-23.

91. Jiefu解腹 has been glossed in different ways. Following Wang Hui, Zhang Yanchang (122) treats this as "draining the abdomen of perverse and poisonous substances as well as static congelations of qi (jieqi 結氣)." Our reading, however, draws upon Qianjin yaofang, which contains a virtually identical formula. There, the author proposed using dahuang 大黃 to induce diarrhea in order to clear obstructions in the abdomen. On this point, see Qianjin yaofang, 9/168.

92. The Wuwei editors (7), Akahori and Yamada (378), and Zhang Yanchang (122) have filled in the blanks with the following characters: bing ye hehuo yi 並冶合和。以. This is certainly plausible, but the current photograph is too unclear for us to verify the characters on the strip.

93. Akahori and Yamada (378) punctuate the lines differently from us, though their translation on 379 is closer to ours in meaning. They punctuate after the first occurrence of jie 解 but do not punctuate after fang 方 or, later, after $y u$ 愈.

94. Strip 43 ends with a reference to Cold Damage disorders. The Wuwei editors (7) believe that the text is incomplete, so it is uncertain whether the reference to Cold Damage has anything to do with the preceding text. Akahori and Yamada (378), however, hint through their punctuation that the aforementioned formula also treats cases of Cold Damage, too. Too little context, however, survives for us to determine whether the formula supplied on strips $42-43$ have anything to do with Cold Damage. 
6 fen each of Bark of Magnolia [Magnolia officinalis]; Gypsum; and Shrubby Sophora [Sophora flavescens].

2 fen each of Rhizome of Chinese or Szechuan aconite; and Szechuan aconite root.

All seven of these substances. [5 illegible characters.] Drink one squareinch spoonful [2.76 ml]. Extremely efficacious. This will cure all cases [described above]. For Cold Damage and for expelling winds (?) ...

\section{Strips 44-45}

I 治心腹大積, 上下行如虫狀, 大急方：班髦 95 十枚，地肹 96 一枚，桂一 寸, 凡三物皆并 44

冶合和, 使病者宿冊食, 旦飲藥一刀圭, 以肥美 97 丮宊 98 , 十日壹飲藥, 如有徵 99 當出。從 ${ }^{100} 45$

A formula to treat a large accumulation in the heart and abdomen, which moves above and below in the shape of a worm and is very painful:

Cantharides, 10 pieces (mei).

Blue-black Beetle, 1 piece (mei).

Bark of cassia, 1 cun $[2.375 \mathrm{~cm}]$.

Pulverize, mix, and combine all three of these substances. Make sure that the ill does not eat at night but drinks one knifeful [0.276 ml] of the

95. Banmao 斑髦 is a variant of banmao 斑蝥 or 斑貓; cf. Wuwei editors (7), Akahori and Yamada (379, n. 112), and Zhang Yanchang (123).

96. Didan 地脤 is a variant of didan 地膽。Dan 肹 is a variant of dan 膽; cf. Wuwei editors (7), Akahori and Yamada (379), and Zhang Yanchang (123).

97. Transcriptions vary. The Wuwei editors (7), Akahori and Yamada (379), and Zhang Yanchang (122) all transcribe the characters on strip 45 as feimei 肥美. Zhang Lijun 張麗君 (“Wuwei Handai yijian XX kaoshi” 武威漢代醫簡册完考釋, Zhonghua yishi zazhi 中華醫史雜誌 1996.1, 53) renders the characters as yimei 肊美. Our reading of the graph on the photograph supports, however, the Wuwei editors' transcription.

98. He Shuangquan (39) and Zhang Yanchang (123) transcribe the characters after feimei 肥美 as bise 閉塞. Akahori and Yamada $(379, n$. 116) provide a different transcription of the non-standard characters, but say that the meaning of those characters is unclear. The Wuwei editors do not transcribe the two characters after feimei, being unable to recognize them. We too were unable to recognize the characters from the photograph.

99. Zheng 徵 is a variant of zheng 痽 (obstruction) or zhengjia 㿈瘕 (concretion); cf. Wuwei editors (7) and Akahori and Yamada (379, n. 117).

10o. There may be punctuation after chu 出 and before cong 從, though we were unable to verify this from the photograph. Zhang Yanchang (123) believes this is a sign that the cong should be the beginning of another strip. 
medicine at dawn. In cases where the [afflicted] is corpulent ... [2 unrecognizable characters.] Drink the medicine once every ten days. [Ailments] like concretion should be expelled.

From ...

\section{Strips $46-47$}

I治伏梁裹膿在胃腸之外方 : 大黃 $=$ (黃) 芩、勺藥各一兩, 消石 ${ }^{101}$ 二 兩, 桂一尺, 46

桑卑肖 ${ }^{102}$ 十四枚, 膺虫 ${ }^{103}$ 三枚, 凡七物皆父且, 漬以淳酒五升, 卒時 ${ }^{104}$, 煮 之三 47

A formula to treat cases of fuliang ${ }^{105}$ with pus outside of the stomach and intestines:

One liang [13.8 g] each of Rhubarb; Baical skullcap; and Peony.

Epsom Salts, 2 liang [27.6 g].

Bark of cassia, 1 chi $[23.75 \mathrm{~cm}]$.

Praying Mantis egg case on mulberry branch, 14 pieces (mei).

Wingless cockroach [Eupolyphaga], 3 pieces (mei).

Mince and then soak all seven of these substances in five sheng [1000 $\mathrm{ml}]$ of a fine strongly-flavored alcohol for one night and one day. Boil it three (?) ...

101. Xiaoshi 消石 is a variant of xiaoshi 硝石; see Akahori and Yamada (380) and Zhang Yanchang (123). Sivin (277) renders xiaoshi as Epsom Salts, whereas Barrett (373) translates the term as saltpeter or potassium nitrate. Since Sivin's rendering is based on an analysis of a Tang sample, we follow him here.

102. Sangbeixiao 桑卑肖 is another name of sangpiaoxiao 桑螵蛸; see Wuwei editors (7), Akahori and Yamada (381), and Zhang Yanchang (123).

103. The Zhonghua renmin gongheguo yaodian 中華人民共和國藥典 identifies zhechong 䗪虫 as tubie 土䧸 or Ground Beetle. On this point, see Guojia yaodian weiyuan hui 國家藥典委員會, ed., Zhonghua renmin gongheguo yaodian, yibu 中華人民共和 國藥典 (一部) (Beijing: Huaxue gongye chubanshe, 2015), 15.

104. $Z u$ 卒 is a variant of $z u i$ 晬, meaning one night and day (24 hours); cf. Wuwei editors (7), Akahori and Yamada (380, n. 126), and Zhang Yanchang (123). Here, our punctuation departs from Akahori and Yamada (380), who punctuate after sheng 升. Instead, we follow Zhang Yanchang (123). Zhang's punctuation makes more sense, since soaking for one day seems more plausible than boiling for a full day.

105. Fuliang 伏梁 is the name of an illness in the Neijing and other ancient texts, which is explained differently. For various explanations, see Li Jingwei 李經緯 and Deng Tietao 鄧鐵濤, eds., Zhongyi dacidian 中醫大辭典 (Beijing: Renmin weisheng, 1995), 560. There, fuliang is explained in three ways: as an accumulation in the heart, a swelling of the waist, and an abscess below the navel. 


\section{Strips $48-49$}

去中令 ${ }^{106}$ 病後不复發用宊方 : 穾 ${ }^{107}$ 地長與人等，深七尺，橫五尺，用白 羊108矢乾之。十餘石置其48

阬 ${ }^{109}$ 中, 從 ${ }^{110}$ 火其上, 羊矢盡索, 橫木阬上 ${ }^{111}$, 取其臥 ${ }^{112}$, 人臥其阬 上，熱氣盡乃止。其病者，慎勾得出見。49

A formula to get rid of internal [coldness], causing the illness not to return afterwards ... [text uninterpretable because of two unknown characters]. Dig a hole in the ground as long as a person, seven chi [166.25 cm] in depth and $5 \mathrm{chi}[118.75 \mathrm{~cm}]$ in width. Use the dung of a white sheep, drying it. Place over ten dan [264 kg] $]^{113}$ of the dung inside the pit, applying fire to the top. Once the sheep's dung has been completely burned, lay a log horizontally on top of the pit to make a bed (?). Have the ill sleep on top of the pit. Stop when the hot qi is exhausted. The ill should be careful not to go out or be exposed ...

\section{Strips 50-51}

【治金創內漏, 血不出方 : 藥用大黃自 ${ }^{114}$ 二分, 曾青二分, 消石 ${ }^{115}$ 二分, 䗪 虫三分，䖟 50

106. Ling 令 is a variant of leng 冷; cf. Wuwei editors (8) and Akahori and Yamada (381, n. 128).

107. Chuan 萓 is a variant of chuan 穿; Wuwei editors (8), Akahori and Yamada (381, n. 129), and Zhang Yanchang (124).

108. Yangshi 羊矢 is a phonetic loan for yangshi 羊屎. (See n. 48 above.)

109. Keng 阬 is a variant form of keng 坑; cf. Wuwei editors (8) and Zhang Yanchang (124).

110. Cong 從 is a variant of zong 縱; cf. Zhang Yanchang (124).

111. Our punctuation departs from that of Akahori and Yamada (381) and Zhang Yanchang (124), who punctuate the line as 羊矢盡。索横木坑上, 取其臥。We could not make sense of the grammar of the sentence with this punctuation. To support our reading, it is worth noting two points: first, suo 索 can mean jin 盡 (to complete or exhaust), and heng 横 can be used as a verb meaning "to lay horizontally."

112. The meaning of qu qi wo 取其臥 is unclear.

113. This strikes us as an excessive amount of dung. Another possible reading of dan 石 is not as a measurement of weight but rather of capacity. According to the Hanyu da cidian, one dan is equal to 10 dou 斗 (20,000 ml).

114. Dahuang rou 大黃自 probably refers to dahuang dan 大黃丹 (Big Minium). For this translation, see Sivin (279). However, opinions divide on this subject. Zhang Yanchang quotes Liu Gang 劉綱, who argues that the graph in question can be read as either rou or dan, but the substance refers in either case to rhubarb. On this point, see Liu Gang, “Wuwei Handai yijian dahuang kaoshi" 武威漢代醫簡大黃考釋, Zhongyaocai 中藥材 1986.5, 44. Wang Hui ("Wuwei Handai yijian," 123), in contrast, maintains that the graph certainly refers to the heart of rhubarb. However, Akahori and Yamada (382, n. 131) argue that the character should be read as dan, because the two substances that follow are minerals. In their view, dahuang dan refers to qiandan 鉛丹 (red lead). While we accept this transcription, we believe that the equation of dahuang dan with qiandan is speculative.

115. Xiaoshi 消石 is a variant of xiaoshi 硝石; cf. Akahori and Yamada (380) and Zhang Yanchang (123). 
頭 ${ }^{116}$ 二分, 凡五物皆冶合和, 以方寸七一, 酒飲。不過, 再飲, 血立 出, 不即從大便出。51

A formula to treat a metal wound with internal leakages where the blood does not come out. The medicine uses:

Big Minium, 2 fen.

Malachite or Laminar, 2 fen.

Epsom Salts, 2 fen.

Wingless cockroach, 3 fen.

Mengtou, 2 fen.

Pulverize, combine, and mix all five of these substances. With alcohol, drink one square-inch spoonful $(2.76 \mathrm{ml})$. If insufficient, drink another dose. The blood will immediately come out; if not, it will come out in the stool.

\section{Strips 52-53}

治金創止汿 ${ }^{117}$ 方 : 石膏一分, 藓二分, 甘草一分, 桂一分, 凡四物皆冶 合和, 以方寸寸 ${ }^{118}$, 酢 52

漿119飲之, 日再夜一, 良甚, 勿傳也。53

A formula to treat a metal wound and to stop the pain:

Gypsum, 1 fen.

Ginger, 2 fen.

Licorice [Glycyrrhiza uralensis], 1 fen.

Cassia twigs, I fen.

Pulverize, combine, and mix all four of these substances. With bitter alcohol, drink one square-inch spoonful $(2.76 \mathrm{ml})$. Drink it twice during

116. There are different opinions as to the identification of mengtou 䖟頭. The Wuwei editors (8) raise the possibility that meng 虻 and mengtou 虻頭 were not the same substance. Zhang Yanchang, in contrast (124, n. 3), argues that mengtou 䖟頭 refers to some kind of chong 蟲 (insect, worm). Akahori and Yamada (382, n. 132) seem to think that mengtou refers to meng 虬.

117. Yong 汿 is a variant of tong 痛; cf. Wuwei editors (8), Akahori and Yamada (382, n. 133), and Zhang Yanchang (125).

118. Fang cun cun 方寸寸 has been miswritten for fang cun bi 方寸七; see Wuwei editors (8), Akahori and Yamada (382, n. 136), and Zhang Yanchang (125, n. 2).

119. Cujiang 酢漿 can be interpreted variously. Zhang Yanchang argues that $c u$ means $c u$ 醋.The Wuwei editors (8) argue that cujiang can refer either to $c u$ 醋 (vinegar) or to suanjiu 酸酒 (bitter alcohol). We believe that the second reading is superior, because, in the Wuwei corpus, medicine was often administered with alcohol. 
the day and once again at night. Extremely efficacious. Do not transmit this formula.

\section{Strip 54}

【治金腸出方：冶龍骨三指撮, 以鼓汁飲之, 日再 ${ }^{120}$, 三飲腸自為入, 大良，勿傳也。 54

A formula for treating metal [wounds] in which the intestines have spilled out:

Pulverize three-finger pinches of fossil bone and drink with fermented bean juice. Drink it twice during the day. After three drinks, the intestines will contract on their own. Very efficacious. Do not transmit.

\section{Strips 55-56}

【治 $\square \square \square \square \square \square \square{ }^{121}$ 潰，醫不能治，禁方其不愈者 ${ }^{122}$ : 半夏、白斂 ${ }^{123}$ 、勺 藥、細辛、 55

烏喙、赤石脂、貸赫 ${ }^{24}$ 、赤豆初生未臥者、暮替 ${ }^{125}$, 凡九物, 皆并冶 合，其分各等，合和 56

To treat [7 illegible graphs] festering ... Cases that healers cannot treat. For those who cannot be cured by proscribed formulas:

Panhsia [Pinellia ternata]; Ampelopsis [Ampelopsis japonica]; Peony; Chinese wild ginger; rhizome of Chinese or Szechuan aconite; Halloysite; Hematite; small adzuki beans when they first sprout; and the excrement of silk worms.

120. There are two potential ways of punctuating the line; one in which we punctuate after zai 再, and another one after yin 飲. Akahori and Yamada (383) and Zhang Yanchang (125) punctuate in the latter fashion without explanation. In the former, the line would read "[drink] twice a day, and after 3 times ..." This interpretation would allow us to know how long the drug would be administered before seeing improvement. In the latter interpretation, the line would read: "each day, drink two to three times." We prefer the former explanation because it is consistent with the information presented in many of the other formulas in the corpus, which states the period of a drug's administration.

121. The Wuwei editors (9) and Zhang Yanchang (125) leave six blank spaces for illegible characters. Akahori and Yamada (383) leave seven. After examining the photograph of the strip, we concur with the latter opinion.

122. Akahori and Yamada (383) and Zhang Yanchang (125) punctuate this line differently: 醫不能治禁方 (a proscribed formula that healers cannot make). We propose to punctuate after zhi 治 and treat jinfang 禁方 as the subject of the next sentence (which would otherwise be missing).

123. Bailian 白斂 is a variant of bailian 白䰻.

124. Daizhe 貸赫 is a variant of daizhe 代赫, which is short for daizheshi 代赫石 (Hematite); cf. Wuwei editors (9) and Zhang Yanchang (126, n. 2).

125. Canshi 暮矢 is a variant of canshi 敏屎; see Wuwei editors (9), Akahori and Yamada (383, n. 146), and Zhang Yanchang (126, n. 3). 
Pulverize and combine all nine of these substances. The portions will be equal. Combine and mix ...

\section{Strips 57-67}

治千金膏藥方：蜀椒四升、弓窮一升、白茝 ${ }^{26}$ 一升、付子世果，凡四物 57 皆冶、父且, 置銅器中, 用淳滆 ${ }^{127}$ 三升漬之, 卒時。取韻 ${ }^{128}$ 豬肪三斤先 前 ${ }^{129} 58$

之。先取雞子中黃者置梧 ${ }^{130}$ 中, 撓之三百, 取藥成以五分七一, 置雞子 中, 复 59

撓之二百。薄 ${ }^{13}$ 以塗132其雍者, 上空者遺之中央, 大如錢。133 藥乾, 復 塗之如 60

前法, 三塗, 去其故藥。其冊農134者, 行㗹; 已有農者, 潰。冊得力 作，禁食諸采。61

A formula for a medicinal paste worth a thousand coins:

Szechuan pepper, 4 sheng [80o ml].

Szechuan lovage, 1 sheng [200 $\mathrm{ml}]$.

126. Baizhi 百茝 is a variant of baizhi 白芷; see Akahori and Yamada $(384, n$. 149). The character is miswritten in the transcription of the Wuwei editors (10) and Zhang Yanchang (126).

127. $X i$ 溢 is a variant for $x i$ 䤈 (deeply sour); cf. Wuwei (10), Akahori and Yamada $(385$, n. 151), and Zhang Yanchang (127, n. 1).

128. Fen 顡 is a variant of fen 獖 (neutered pig); cf. Wuwei (10), Akahori and Yamada $(385$, n. 151), and Zhang Yanchang $(127$, n. 2).

129. Qian 前 is a variant of jian 煎; see Wuwei (10), Akahori and Yamada (385, n. 152), and Zhang Yanchang (127, n. 3).

130. $W u$ 梧 is possibly an error for bei 桮; cf. Wuwei editors (10), Akahori and Yamada $(385$, n. 153), and Zhang Yanchang $(127$, n. 4).

131. For the fifth character on strip 6o, the Wuwei editors (10) have written bao 薄, but Akahori and Yamada (384) transcribe it is as dang 蕩. We checked the photograph and we think that the graph is the former.

132. The Wuwei editors (10) transcribe this character as $t u$ 涂, a variant of $t u$ 塗, throughout the manuscripts. We checked the photographs of the strips, and we believe that the latter is the correct transcription.

133. Our punctuation departs from that of Zhang Yanchang (126): 薄以塗其雍者 上, 空者遺之, 中央大如錢。Instead, we follow Akahori and Yamada (384) here, as their interpretation makes the most sense.

134. Nong 農 is a variant of nong 膿; see Wuwei (10), Akahori and Yamada (385, n. 158), Zhang Yanchang (127, n. 8). 
Fragrant Angelica [Angelica anomala or A. dahurica], 1 sheng [200 ml].

Szechuan aconite root, 30 heads $(k e)$.

Pulverize and mince all four of these substances and place inside of a bronze vessel. Use three sheng [600 $\mathrm{ml}$ ] of pure, strong vinegar to soak the ingredients for one night and one day. Take three jin [66o g] of fat from a neutered pig, frying it first. Extracting the yolks of the chicken eggs, first place them in a cup and then stir the insides 300 times. Fill one-fifth of a spoonful of the medicine inside of the chicken eggs, stirring them 200 more times. Apply a thin layer of the medicine to the swelling. Leave a hole as big as a coin at the center [of the swelling]. When the medicine has dried, spread it again along the model of the previous layer. Spread three layers and remove the old medicine. Those without pus will immediately be cured, whereas those already with pus will experience festering. Those with swelling should not exert themselves by laboring. Eating all vegetables is proscribed.

\section{Strip 62}

$\square$ 置 $\square$ 上。良甚。創恿座皆中之，良。勿傳也。62

[ 1 illegible character] place [ 1 illegible character] on the upper part. Extremely efficacious. For all cases in which there is pain or swelling in the wound, [the medicine] will be effective. Efficacious. Do not transmit.

\section{Strips 63-67}

逆氣, 吞之; 喉痺, 吞之, 摩之; 心腹急, 吞之; 嗌急, 吞之; 血府 ${ }^{135}$ 恿, 吞之, 摩之; 咽 $63^{136}$

乾, 摩之; 齒急, 塗之; 昏衂 ${ }^{137}$, 塗之; 鼻中生葱 ${ }^{138}$ 傷, 塗之, 亦可吞 之。皆大如 64

135. Xuefu 血府 means "uterus"; see Wuwei (10) and Akahori and Yamada (385, n. 163), though Akahori and Yamada are uncertain about this identification. Zhang Yanchang $(127, \mathrm{n} .10)$ does not provide support for his reading, but speculates that xuefu refers to the lower abdomen.

136. We note that the physical placement of characters on strips $64-65$ does not match those on strips 62-63. The latter has two characters before the first binding cord, whereas the former has just one character. However, we have grouped these strips together because of their similar contents.

137. Hunnï 昏皿 refers to an illness that causes the nose to bleed, and the eyes to go black and blind (mienü 蠛畔); see Wuwei editors (10). Zhang Yanchang (127, n. 11) glosses this as a case of nosebleeds coupled with dizziness.

138. E 蓸 is a variant of $e$ 惡, an illness caused by rotting in the blood and qi; see Wuwei (10), Akahori and Yamada (385, n. 165), and Zhang Yanchang (127, n. 12). 
酸籴, 稍咽之, 腸中有益為度, 摩之, 皆三, 乾而止。此方禁。又中奶 人乳餘 13965

疾, 吞之。氣龍 ${ }^{140}$, 裹藥以縠 ${ }^{141}$, 塞之耳, 日壹易之。金創塗之, 頭恿風 塗 66

之, 以三指摩 $\square$ 。 $\square \square \square$ 疝吞之, 身生葽氣塗之。此膏藥大良, 勿得 傳。 $67^{14^{2}}$

For qi reversal, swallow it [i.e., the medicine]. For throat paralysis, swallow it and rub it [into the affected area]. For heart or abdominal pain, swallow it. For throat pain, swallow it. For uterine pain, swallow it and then rub it [into the affected area]. For dry throat, rub it [into the area]. For tooth pain, spread a layer. For mienü [i.e., an affliction in which the nose bleeds and the eyes blacken], spread a layer. For wounds that cause the blood and $q i$ inside of the nose to rot, spread a layer. It can also be swallowed in such cases. For all of these cases, the dose should be as

139. Fu 奶 is a variant of $f u$ 婦; Wuwei (10), Akahori and Yamada $(385$, n. 167), and Zhang Yanchang $(127, \mathrm{n} .13)$. Ruyu 乳餘 is a postpartum illness.

140. Long 龍 is possibly an error for long 襲; see Wuwei (10), Akahori and Yamada (386, n. 169), and Zhang Yanchang (127, n. 14).

141. $H u$ 縠 is a fabric made of spun yarn; see Wuwei (10) and Zhang Yanchang (127, n. 15).

142. The Wuwei editors (10) were uncertain about whether strips $57-67$ fit together and how. They presented two different theories: (1) the strips belonged to the same formula, but there is a missing strip between 61 and 62 (they argue that the contents of these two strips are unrelated); (2) the second theory, which focuses on differences in handwriting and the lack of cohesion between strips, maintains that the strips are out of order. In this view, strips $57-61,63,66$, and 67 belong to one set, whereas 62,64 , and 65 belong to a second set.

We agree that strip 62 is most likely out of place and does not belong to the formula. But we see no problem of placing 63-67 together, because women's ailments appear in both strip 63 (uterus) and strip 65 (engorgement of the breasts). Admittedly, it is odd that there are multiple references to prohibitions, which appear throughout this set of strips and not at the end (where they generally appear in the Wuwei corpus), but we note three points in favor of placing strips 65 and 66 together. First, the discussion of engorgement at the end of strip 65 is itself anomalous. The scribe placed this discussion after what should have been the end of the formula, thereby presenting the treatment of engorgement as an afterthought, as an additional condition treated by the same formula. In this way, the inclusion of additional conditions on strip 66 is actually consistent with the pattern observed on the preceding strip (65). Second, our examination of the photograph of strip 66 reveals that the first character is $j i$ 疾, which fits together with the final characters at the end of strip 65 (ruyu 乳餘). Taken together, the three characters 乳餘疾 ruyu ji mean "the condition of engorgement" or "engorgement." Third, the handwriting and the arrangement of the characters on both strips 65 and 66 match, thereby indicating that the contents belong together. 
large as a sour date. One can swallow it little by little. Use as much as needed to see improvement in the intestines. For all of these illnesses, rub it in three times, stopping after it has dried. These formulas are all proscribed. This formula is also effective for women suffering from engorgement. Swallow it. For qilong [i.e., deafness], wrap the medicine with a gauze and place it in the ear canal. Change the dressing once a day. For metal wounds, spread a layer of the medicine. For headaches from wind (?), ${ }^{143}$ spread a layer using a three-finger pinch of the medicine to rub it in [4 illegible characters]. For hernias, swallow it. For cases where the body generates bad $q i$, spread it. The medicinal paste is very efficacious; do not transmit.

\section{Strips 68-71}

六日脛中當急 $=$ (恿) 至足下, 傷膿出, 逐服之, 世日知愈。六十日, 須 麇 ${ }^{144}$ 生, 音毊雖㯕敗能復精。鼻柱 ${ }^{145} 、 68$

鼻中當苻 ${ }^{146}$, 血出 ${ }^{147}$ 。若膿出, 去死月, 藥用代盧如 ${ }^{148}$ 、巴豆各一分, 并合和，以絮裹藥塞鼻，諸息月皆 69

出。不出, 更飲調中藥= (藥) 用亭磨149二分, 甘遂二分, 大黃一分, 冶 合和, 以米汁, 飲一刀圭, 日三四飲, 徵出乃止。即鼻不利, 70

143. The Suwen (Fenglun pian di sishier 風論篇第四十二) explains toutong feng 頭痛 風 as a wind illness affecting the head, in which the face sweats from the influence of a nefarious wind. See Zhang Yinan 張隐菴, ed., Huangdi neijing suwen jizhu 黃帝內經素 問集註 (Shanghai: Shanghai kexuejishu, 1959), juan 5, “Feng lun” 風論, 164.

144. Xumi 須麇 is xumei 䰅眉 with $m i$ 麇 (Schuessler $26-39<\mathrm{LH}{ }^{*} \mathrm{mi}$ ) being a phonetic loan for mei 眉 (Schuessler 27-14< LH * mi); cf. Wuwei (11), Akahori and Yamada $(387$, n. 174), and Zhang Yanchang (128, n. 2).

145. We have punctuated strip 68 differently from Akahori and Yamada (387), who read the following as belonging to one sentence: 能復精鼻柱. But we could not make sense of the grammar with this punctuation. Akahori and Yamada also treat the formula on strip 68 as belonging to a different formula from $69-71$.

146. The graph 佾 is a variant of $f u$ 腐; see Wuwei (11); cf. Akahori and Yamada (387, n. 177), and Zhang Yanchang (128, n. 4).

147. Akahori and Yamada punctuate the beginning of strip 69 differently. They treat fuxue 腐血 as a single compound.

148. The Wuwei editors (11), Akahori and Yamada (387, n. 178), and Zhang Yanchang (128, n. 5) interpret dailuru 代盧如 as another name of dailüru 代䕡茹.

149. The Wuwei editors (11), Akahori and Yamada (388, n. 181) and Zhang (128, n. 7) interpret tingmo 亭磨 as an error for tingli 艼藶. 
藥用利盧 150 一本 ${ }^{151}$, 亭磨二分, 付子一分, 早152萊一分, 皆并父且, 合 和, 以醇汪漬, 卒時。去宰, 以汁灌其鼻中。71

... Six days, pain inside of the shins, which reaches up to the bottom of the feet and where pus comes out of the wound. Take [the medicine] for 30 days and you will be cured. If one takes the medicine for 60 days, the eyebrows and beard should then grow back, and even if the voice is still hoarse, it may be made clear again. The nose pillar and the inside of the nose will rot, and blood will come out. If pus emerges and you wish to expel the dead flesh, the medicine uses spurge [Euphorbia] ${ }^{153}$ from Dai and Croton [Croton tiglium], one fen each. Combine and mix both of them. Using cotton, wrap the medicine to stop up the nose, and the piles in the nose will emerge. If they do not come out, drink a medicine that regulates the belly. The medicine uses:

Woods-whitlow grass [Draba nemorosa or Lepidium apetalum], 2 fen.

Kansui [Euphorbia kansui], 2 fen.

Rhubarb, 1 fen.

Pulverize, combine, and mix. With rice juice, drink one knifeful [0.276 ml] of the medicine three to four times a day. When a bit of the flesh comes out, stop taking the medicine.

If the nose is congested, then use for medicine:

False hellebore [Veratrum nigrum or V. maackii], I stalk.

Woods-whitlow grass, 2 fen.

Szechuan aconite root, 1 fen.

Zaojia [Gleditsia sinensis], I fen.

Mince, combine, and mix all of these substances. Soak the substances for one night and one day in pure vinegar and then remove the sediment. Use the medicinal juice to irrigate the inside of the nose.

150. Lilu 利盧 is a phonetic loan for lilu 菉蘆; $l i$ 利 (Schuessler 26-24< LH *lic) is the phonetic loan for $l i$ 藜 (Schuessler 26-24 < LH *lei); cf. Baxter (Personal Correspondence); Wuwei (11) and Zhang Yanchang (128, n. 9).

151. Akahori and Yamada $(383$, n. 184) believe that ben 本 is an error for fen 分. However, the line makes sense as is, since ben can mean gen 根.

152. Zao 早 $\left(\right.$ Schuessler $13-51<\mathrm{LH}^{*} \mathrm{tsou}^{\mathrm{B}}$ ) is a phonetic loan for zao 皇 (Schuessler 13-56< LH *dzou ${ }^{\mathrm{B}}$ ); see Wuwei (11), Akahori and Yamada (388, n. 185), and Zhang Yanchang (128, n. 10). For our translation, see Barrett (373).

153. Neither $\mathrm{Hu}$ nor Barrett offer a translation of luru, so we follow Read, Chinese Medicinal Plants, \#323, in rendering the term as spurge. 


\section{Strip 72}

口徵154當下，從大便出。72

[Indeterminate number of missing characters] ... The concretion will descend. Afterwards, it will emerge from a bowel movement.

\section{Strip 73}

$\square$ [病 $]^{155} \square$ 老瘦者, 以人事咸 ${ }^{156}$ 之。此藥亦中治毒養, 如 73

[The strip is too fragmentary for us to interpret]

\section{Strip 74}

口飲食, 數[驗]157, 禁, 不傳也。74

[Indeterminate number of missing characters] ... Eat and drink. Repeatedly tested. Proscribed; do not transmit.

\section{Strip 75}

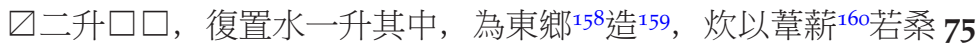

[Indeterminate number of missing characters] ... two sheng [400 ml] [2 illegible characters], then placing one sheng [200 $\mathrm{ml}$ ] of water inside. Place the medicine in a stove facing east, cooking it together with reed or mulberry.

154. The graph for zheng 徵 is not clear from the photographs. Zheng may be a variant of zheng 癄 (concretion).

155. The Wuwei editors (11) do not transcribe any of the characters before lao $\frac{}{t}$; cf. Zhang Yanchang (128). Akahori and Yamada (389) also transcribe this line differently from the Wuwei editors: they add chang 長 before bing 病 without explanation. We could not verify the chang 長 from the photograph of the strip, but the phonetic element bing 丙 for bing 病 is clear. Chen Guoqing 陳國清 however identified the bing 病 from the strip; see Chen Guoqing 陳國清, “Wuwei Handai yijian shiwen zai buzheng”武威 漢代醫簡釋文再補正, Kaogu yu wenwu 考古與文物 1991.3, 91-93; 92.

156. Xian 咸 is a variant of gan 感; cf. Akahori and Yamada (389, n. 187). Wuwei (11) and Zhang Yanchang (129) transcribe the character as gan 感. The photograph of the strip suggests xian.

157. The Wuwei editors (11) do not transcribe yan 驗; cf. Akahori and Yamada (389). Our review of the photograph suggested that the graph was clear enough. It is also transcribed by Zhang Yanchang (128).

158. Xiang 鄉 (Schuessler $3^{-16}<\mathrm{LH}{ }^{*} \mathrm{hian}^{\mathrm{B}}$ ) is a phonetic loan for xiang 向 (Schuessler $3-18<\mathrm{LH}^{*}$ hianc); on this point, see Akahori and Yamada $(389, \mathrm{n} .190)$ and Zhang Yanchang (129, n. 3).

159. Zao 造 can mean zao 灶/䆠; on this point, see Wuwei editors (12), Akahori and Yamada (389, n. 190), and Zhang Yanchang (129, n. 3).

160. Akahori and Yamada (389) punctuate differently, stopping after weixin 莘薪. This reading is possible, but we note that ruo 若 can mean huo 或 (or). 


\section{Strip 76}

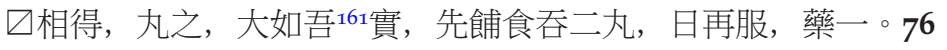

... [Indeterminate number of missing characters] ... mutually attained (?). Make it into a pellet as big as the seed of a parasol tree. Before supper, swallow two pellets. During that day, take the medicine again. This time, take one.

\section{Strip 77}

$\triangle \square \square$ 梵 ${ }^{162}$ 四兩, 消石二兩, 人參、方風、細辛各一兩, 肥呆五。77

[Indeterminate number of missing characters and 2 illegible characters] ...

Alums, 4 liang [55.2 g].

Epsom Salts, 2 liang [27.6 g].

One liang [13.8 g] each of ginseng [Panax ginseng]; Fangfeng; and Chinese wild ginger.

Chinese gymnocladus [Gymnocladus chinensis], five ...

\section{Strip 78}

】右治百病方。78

... To the right, formulas to treat the many ailments:

\section{Tablets}

\section{Tablets 79A-B}

治久欬上氣, 喉中如百蟲鳴狀, 业歲以上方 : 茈胡、枯 ${ }^{163}$ 梗、蜀椒各二 分, 桂、烏喙、薑各一分, 凡六物 $79 \mathrm{~A}$

皆冶合和，丸白蜜，大如嬰桃。書夜含三丸，稍咽之，甚良。79B

A formula to treat those over thirty years of age who have a persistent cough, qi rising, and something in the throat that sounds like [the crying of a] hundred insects [wheezing?]:

161. $W u$ 吾 is a variant of $w u$ 梧.

162. Fan 梵 is a variant of fan 矾. The character is transcribed neither by the Wuwei editors (11) nor by Akahori and Yamada. It is however transcribed by Zhang Yanchang (129), and it is clear enough from the photograph.

163. $K u$ 枯 is possibly an error for jie 桔; cf. Wuwei (12) and Zhang Yanchang (130, n. 1). 
Two fen each of Hare's ear root; root of balloon flower; and Szechuan pepper.

One fen each of cassia twigs; rhizome of Chinese or Szechuan aconite; and ginger.

Pulverize, combine, and mix all of these six substances. With white honey, make them into pellets the size of cherries. Hold three pellets in the mouth over a twenty-four-hour period. Swallow the resulting juice little by little. Extremely efficacious. ${ }^{164}$

\section{Tablets $80 \mathrm{~A}-80 \mathrm{~B}$}

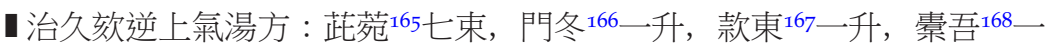
升，石

膏半升, 白 $\square$ 一 $\square^{169}$, 桂一尺, 密半升, 妻曲枚, 半夏十枚, 凡十物皆 父且。80A

半夏母父且, 洎水斗六升, 炊令六沸, 浚去宰, 溫飲一小桮, 日三飲, 即藥

宿，當更沸之。不過三四日逾170。8oB

A formula for a decoction to treat a persistent cough, as well as qi reversal and counterflow:

164. The formula matches the contents of strips $3-5$, with minor variation in language at the end.

165. Ziwan 茈苑 is a variant of ziwan 紫苑; cf. Wuwei (13), Akahori and Yamada (391, n. 196), and Zhang Yanchang (130, n. 1). For our translation, see Barrett (373); no translation of the two-character compound is found in $\mathrm{Hu}$.

166. There is some question as to whether mengdong 門冬 refers to tianmendong 天門 冬 (Chinese asparagus root) or maimendong 麥門冬 (Lily turf). See Wuwei (13), Akahori and Yamada (391, n. 197), and Zhang Yanchang (131, n. 2).

167. Dong 東 is an error for dong 冬; cf. Wuwei editors (13), Zhang Yanchang (130, $\mathrm{n}$. 2), and Akahori and Yamada (391, nn. 197-98).

168. The meaning of tuowu 㪙吾 is unclear. Akahori and Yamada (391, n. 199) argue that tuowu refers to kuandong hua 款冬花 (Tussilago flower). Zhang Yanchang (130, n. 4), however, argues that tuowu is another name for lotus seed pod (lianpeng cao 蓮蓬 草). The Wuwei editors (13) do not provide a firm answer, but suggest that tuowu refers to something different from kuandong, since the binome follows that substance on the list. Zhang Xiancheng 張顯成 thinks that tuowu is guijiu 鬼臼. On this point, see Zhang Xiancheng, “Tuowu ji guijiu- jianbo yishu duanzha” 㯻吾即鬼臼一一簡帛醫書短答, Chengdu zhongyi xueyuan xuebao 成都中醫學院學報 1995.1, 18-19.

169. The Wuwei editors (12) tentatively transcribe this graph as shu 束; cf. Zhang Yanchang (130). The character is not transcribed by Akahori and Yamada. The current photograph is too blurred for a confident identification.

170. $Y u$ 逾 is a variant of $y u$ 愈; cf. Wuwei editors (13) and Zhang Yanchang (131, n. 3). 
Aster [Aster tataricus], 7 bundles.

Lily-turf [Ophiopogon japonicus or Liriope spicata or L. gramifolia] [or perhaps Chinese asparagus (Asparagus lucidus or asparagus cochinchinensis)?], 1 sheng [200 $\mathrm{ml}]$.

Tussilago [Tussilago farfara], 1 sheng [200 $\mathrm{ml}]$.

Coltsfoot, ${ }^{171} 1$ sheng [200 ml].

Gypsum, half sheng [100 ml].

White [ 1 illegible character], 1 [ 1 illegible character].

Cassia twigs, 1 chi $[23.75 \mathrm{~cm}]$.

Honey, $1 / 2$ sheng [100 ml].

Jujube [Zizyphus jujuba], 30 pieces (mei).

Panhsia, ${ }^{172}$ Io pieces (mei).

Mince all ten of these substances.

Do not mince the Panhsia. Pour one dou $[2,000 \mathrm{ml}]$ and six sheng $[1,200 \mathrm{ml}]$ of water into a pot, bringing it to a boil six times. Drain and get rid of the sediment. Drink a small cup warm three times a day. If the medicine is used after the night, it should be boiled again. The illness will be cured in three to four days.

\section{Tablet 81}

治痹手足雍種方 : 秦瘳173五分, 付子一分。・凡二物冶合和。半方寸七 一, 先餔飯 ${ }^{174}$ 酒飲, 日三。以愈為度。8

A formula for treating paralysis and swelling in the hand or foot:

Large-leaved gentian [Gentiana macrophylla or G. dahurica], 5 fen.

Szechuan aconite root, I fen.

171. Neither Hu nor Bartlett offers a translation of tuowu 瞢吾; on this point, we rely on Read, Chinese Medicinal Plants, \#49.

172. Hu Shiu-ying has rendered banxia in Wades-Giles, so we follow her.

173. Qinchou 秦疹 is a variant of qinjiao 秦艽; cf. Wuwei (13), Akahori and Yamada (392, n. 203), and Zhang Yanchang (131, n. 1).

174. Here, we are reading fan 飯 to mean shi 食; see Introduction. 
Pulverize, combine, and mix both of these substances. Before supper, drink one-half of a square-inch spoonful with alcohol three times a day, using recovery as the measure of when the medicine [is to be stopped.]

\section{Tablets 82A-B}

I治久泄腸辟 ${ }^{175}$ 臥血 ${ }^{176} \square$ 外裹帶風 ${ }^{177} \square \square \square$ 醫不能治, 皆射 ${ }^{178}$ 去方：黃連 四分, 黃芩、石脂、龍骨、人參、薑、桂各一分, 凡七物皆并冶合。丸 以蜜, 大如彈丸, 先餔82A

食, 以食大湯 ${ }^{179}$ 飲一丸。不知 $\square \square \square \square$, 腸中 $\square^{180}{ }^{8}$ 加甘草二分 ; 多血, 加桂二分 ; 多農, 加石脂二分。 $\square$ 一 $\square \square \square \square \square$; 多 $\square$, 加黃芩一分。 禁鮮魚、豬月。方禁, 良。82B

A formula to treat chronic diarrhea, leaking abdomen where there is blood [and pus] letting in the stool (?) [4 illegible characters and 4 more untranslatable characters] ... cases of illnesses that healers cannot treat and all refuse to see:

\section{Four fen of Golden Thread [Coptis chinensis].}

1 fen each of Baical skullcap; Halloysite, fossil bones, ginseng, ginger root, and cassia twigs.

Pulverize and combine all seven of these substances, making pellets as large as crossbow pellets with honey. Before supper, drink one pellet of medicine with congee.

If there is no improvement [4 illegible characters].

If there is [ 1 illegible character] in the abdomen, add 2 fen of licorice.

If there is a lot of blood, add 2 fen of cassia twigs.

175. Changpi 腸辟 is a variant of changpi 腸澼; cf. Wuwei editors (13) and Akahori and Yamada (392, n. 204). In contrast, Zhang Yanchang (132, n. 2) treats bi/pi 辟 (Schuessler 8-19 $<\mathrm{LH}^{*}$ piek) as a phonetic loan for $b i$ 壁 (Schuessler 8-19< LH *pek), a move that would render the sentence unintelligible.

176. Woxue 臥血 is hard to interpret. Wuwei (13) and Zhang Yanchang $(132$, n. 2) speculate that the wo 臥 here refers to some form of diarrhea involving the expulsion of pus and blood (xiali nongxue 下痢膿血). This reading makes sense in light of the larger context of the formula, a formula treating blood and pus in the diarrhea.

177. Diverging transcriptions exist of this line. The Wuwei editors (13) do not transcribe wai 外; cf. Akahori and Yamada (392). In addition, the Wuwei editors (13) do not transcribe daifeng 帶風 and instead leave two blanks; cf. Akahori and Yamada (392). Zhang Yanchang (131), however, does transcribe wai 外, which is admittedly blurred, but not daifeng 帶風.

178. She 射 is a variant of xie 謝 (to decline).

179. Shidatang 食大湯 refers to a soup made of rice (mitang 米湯); on this point, see Zhang Yanchang (132, n. 6).

180. The Wuwei editors surmise that the illegible character must be yong 息. 
If there is a lot of pus, then add 2 fen of Halloysite ... [7 illegible characters and 2 untranslatable characters] ... add one fen of Baical skullcap. One is prohibited from eating fresh fish or pork. Proscribed formula; efficacious.

\section{Tablets 83A-83B}

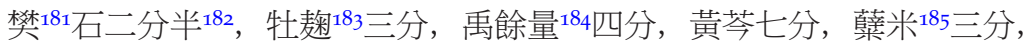

【厚朴三分, 凡六物皆冶合和, 丸以白蜜, 丸大如吾實。旦吞七丸, 餔186 吞九丸, $83 \mathbf{A}$

莫 ${ }^{18} 7$ 吞十一丸。服藥十日知, 小便數多, 廿日愈。公孫君方。 83 B

$2^{1 / 2}$ fen of Kalinite.

3 fen of Mu yeast (?)

4 fen of Limonitum (Clay Ironstone).

7 fen of Baical skullcap.

3 fen of Rice sprout [Oryza sativa].

3 fen of Magnolia Bark.

Pulverize, combine, and mix together all six of these substances. Make into pellets with white honey. The pellets should be as large as a parasol

181. Fan 樊 is a variant of fan 礬; cf. Wuwei editors (14), Akahori and Yamada (393, n. 212), and Zhang Yanchang (132, n. 1). For our translation of fanshi, see Sivin (276), who glosses this term also as a native alum.

182. There appears to be a character after ban 半, which is illegible. The scribe rubbed out the character probably because there was an error in copying. We hold this opinion because the number of intelligible substances matches the number offered by the scribe later in the formula. What's more, the Wuwei editors (14), Akahori and Yamada (393), and Zhang Yanchang (132) do not remark on the missing or illegible characters.

183. Akahori and Yamada (393, n. 213) tentatively identify this substance as a kind of yeast.

184. Liang 量 is a variant of liang 糧; cf. Akahori and Yamada (393, n. 214) and Zhang Yanchang (132, n. 2).

185. Akahori and Yamada (393, n. 215) identify this not as a special variety of rice, but as a rice sprout.

186. According to Zhang Yanchang $(132, n .4), b u$ 餔 (Schuessler $1-67<\mathrm{LH}^{*} \mathrm{pa}^{\mathrm{c}}$ ) is a phonetic loan for $b u$ 晡. Baxter (Personal Correspondence) confirmed the plausibility of this. The Wuwei editors furthermore interpret this as a reference to time. This substitution, though plausible, may be unnecessary. As discussed in the introduction, $b u$ 餔 could refer to bush $i$ 餔時 or supper, a possibility acknowledged by the Wuwei editors (14).

187. Mo 莫 (Schuessler 2-40 $<\mathrm{LH}{ }^{*} \mathrm{ma}^{c}$; ${ }^{*}$ mak) is a phonetic loan for $m u$ 暮 (Schuessler $2-40<\mathrm{LH}^{*} \mathrm{mac}^{\mathrm{c}}$ ); the Wuwei editors (14) and Zhang Yanchang (132, n. 5) see this as a reference to time. 
seed. Swallow seven pellets at dawn. At suppertime, swallow nine pellets. At dusk, swallow 11 pellets. After taking the medicine for ten days, the ill should improve. The urine should be profuse. In twenty days, he or she should be cured. A formula of Master Gongsun.

\section{Tablets 84A-B}

白水侯所奏治男子有七疾方：何謂七疾？一曰陰寒，二曰陰瘘，三曰 苦衰, 四曰精失, 五曰精少, 六曰㯻 ${ }^{188}$ 下養濕, 口不卒, 名曰七疾。 令人陰 $\square$ 小, 㪙下養濕, $\square 2^{189}$, 黃汁出。遠190行, 小便時難。溺 $\square$ 赤黃汨白, $\square$ 便赤膿, 餘酒 $\square$ 苦急。191膝脛寒, 手足熱且煩, 臥不 安牀 ${ }^{192}$, 涓目泣出 $\square$ 下常急, 溫= (溫) 下溜 ${ }^{193}$, 旁 ${ }^{194}$ 急 ${ }^{195}, 84 \mathrm{~A}$

時196蘇 $\square \square \square \square \square$ 陰 $\square$ 有病如此, 名為少餳 197 。何巳 $\square \square \square$ 尚 $\square \square$ 伏 下曰焉 ${ }^{198}$, 巳汻 $\square$ 孫 $\square$ 內餳, 除199 $\square$ 其坐則應中 $\square$, 人不 ${ }^{200}$ 見 $\square \square \square$ 驚 $\square \square$ 酒大樂，久坐不起， $\square$ 便不 $\square$, 有病如此, 終古母子。治之方 : 活

188. Tuo 㯱 refers to yinnang 陰囊 (scrotum); see Wuwei (15), Akahori and Yamada $(395$, n. 226), and Zhang Yanchang $(133$, n. 2).

189. Some disagreements exist as to how to transcribe the character before $z h i$ 之. The Wuwei editors (15) say ying 盈, but Akahori and Yamada (394) write sao 搔 and Zhang Yanchang marks tan 灘 (133). The photograph is too unclear for us to determine which is correct.

190. There is yuan 遠 before xing 行, which Wuwei (15) and Akahori and Yamada omit (394).

191. We are punctuating this line differently from Akahori and Yamada (394), whose transcription reads: 】行小便時難溺。 $\square$ 赤黃泔白 $\square$ 便。赤膿餘。酒 $\square$ 苦息。

192. We are punctuating this line differently from Akahori and Yamada (394), whose transcription reads: 手足熱。且煩臥不安牀。

193. Different interpretations of liu 溜 also exist. The Wuwei editors take it as a reference to a vessel (15), a point on which Akahori and Yamada demur (395, n. 229). Liu can also be used as a verb meaning "to flow." We prefer this reading, since it is consistent with the reference to the bladder, which follows.

194. Pang 旁 is a variant of pang 膀; cf. Wuwei (15), Akahori and Yamada (395, n. 230), and Zhang Yanchang (133, n. 8).

195. We are punctuating the line differently from Akahori and Yamada, and Zhang Yanchang. Akahori and Yamada punctuate the line: $\square$ 下常恿溫溫。下溜旁急。We are reading wenwen 溫溫 ("gently" or "slowly") as an adverb modifying xia 下.

196. The Wuwei editors do not transcribe shi 時; cf. Akahori and Yamada (394), but Zhang Yanchang (133) does. The graph, however, is clear from the photograph.

197. According to the Wuwei editors (15) and Akahori and Yamada (394), shang 飭 is a variant of shang 傷. However, Zhang Yanchang $(134, n$. 1) renders the same character as yang 瘍.

198. The Wuwei editors (15) do not transcribe yan 焉; cf. Akahori and Yamada (394) and Zhang Yanchang (244). The graph, however, is clear from the photograph.

199. The Wuwei editors (15), Akahori and Yamada (394), and Zhang Yanchang (133) omit the chu 除 after neishang 內飭. We checked the photograph, and the graph for chu is clear.

200. The Wuwei editors and Yamada transcribe $84 \mathrm{~B}$ differently, omitting ren bu 人 不 before jian 見. Akahori and Yamada also omit bu 不 after bian 便, which follows. 
樓 ${ }^{201}$ 根十分, 天雄五分, 牛膝四分, 續斷四分, $\square \square$ 五分, 菖蒲二分, 凡六物皆并冶合和, 以方寸七一, 為後飯 ${ }^{202}$, 愈。久病者, 世界日平復, 百日母疾苦。建威耿將軍方, 良, 禁, 千金不傳也。84B

A formula to treat the seven afflictions of men submitted by the Lord of White Waters. What is meant by the seven afflictions? The first is called coldness in the privates; the second is called impotence; the third is called "bitter decline" [i.e., exact meaning unclear]; the fourth is called the loss of essence. The fifth is called small amounts of essence. The sixth is called itchiness and moistness at the base of the scrotum. [Indeterminate number of missing characters] ... no conclusion [i.e., in ejaculating?]. These are called the seven afflictions. This condition causes the privates [illegible character] small ... the base of the scrotum to be itchy and moist ... [ 1 illegible character and 1 untranslatable character], a yellow juice comes out ... [Indeterminate number of missing characters and 2 untranslatable characters] ... Sometimes, there is difficulty in urinating. Urine ... [illegible character] red and yellow milky white. When [illegible character] red pus ... [Indeterminate number of missing characters and 4 untranslatable characters] ... The knees and shins are cold, and the feet and hands are hot and irritated. One does not get rest from sleep. The eyes are watery with tears coming out ... [Indeterminate number of missing characters] ... there will constantly be pain below. Slowly, water will flow, but the bladder will [leak] frequently.

At times, there will be relief ... [5 illegible characters, one untranslatable character, and indeterminate number of missing characters] ... In cases of illness like these, the name is "small damage." [Many untranslatable and illegible characters, as well as an indeterminate number of missing characters.] ... taking great pleasure in alcohol. Sitting for periods of time without rising ... [ 1 illegible character, 2 untranslatable characters, and indeterminate number of missing characters] ... in cases of illness like this, the person is ultimately childless. A formula to treat [these conditions]:

Roots of Trichosanthes [Trichosanthes kirilowii], 1o fen.

Chinese or Szechuan aconite [Aconite chinense or A. carmichaelii], 5 fen. Achyranthes, 4 fen.

Japanese teasel [Dipsacus japonicus], 4 fen.

[2 illegible characters], 5 fen.

Sweetflag or Calamus [Acorus calamus], 2 fen.

201. Huolou 活樓 is a variant of gualou 栝樓 or gualougen 栝樓根; see Akahori and Yamada (396) and Zhang Yanchang (134, n. 2).

202. For the meaning of houfan 後飯, see Introduction. 
Pulverize, combine, and mix all six of these substances, taking them in a square-inch spoon after food. The medicine will cure even those who have been long ill. In thirty days, they will recover; in one hundred days, they will be without suffering. A formula of General Geng of Jianwei. Efficacious. Proscribed. Do not transmit even for 1,00o coins.

\section{Tablets 85A-85B}

$\square$ 分，人脣 203 一分， $\square^{204}$ 之， $\square$ 焦一 $\square ， \square$ 二分， $\square$ 一分，凡八 $\square^{205}$ 冶 合， $\square$, 以溫酒飲方寸七一，日三飲之。呂功君方。有農者，自為 久 ${ }^{206} \square \square \square \square \square \square \square \square$ 出; 有血, 不得為農。・治東海、白水侯所奏 方, 治男子有七疾及七傷。何謂七傷？一日陰寒 ; 二曰陰瘘 ; 三曰陰 衰 ; 四曰軍下 85A

濕而養, 黃汁出, 辛急 ; 五曰小便有餘 ; 六曰荎中急, 如林狀 207 ; 七曰精 自出, 空居獨怒, 臨事不起=（起）死玉門中 ${ }^{208}$, 意常欲得婦人。日甚 者，更而莒 ${ }^{209}$ 輕重，時腹中恿，下弱旁光，此病名曰[內傷]。 $\square \square^{210}$ 桔梗

203. Chang 侌 is a variant of $f a$ 髪; cf. Wuwei editors (15), Yamada (397, n. 237), and Zhang Yanchang (134).

204. The Wuwei editors (15) tentatively transcribe this as fan 煩; cf. Akahori and Yamada (396) and Zhang Yanchang (134). The photograph, however, is too blurred for a confident identification.

205. The Wuwei editors (15) tentatively transcribe this as wu 物; cf. Akahori and Yamada (396) and Zhang Yanchang (134). The photograph, however, is too blurred for a confident identification.

206. Chen Guoqing transcribes jiu 久 as jiao 焦, but we see the graph in the photograph as jiu 久 (Schuessler $4-13<\mathrm{LH}^{*} \mathrm{ku}^{\mathrm{B}}$ ). This can be a phonetic loan for jiu 灭 (Schuessler 4-13 $\left.<\mathrm{LH}{ }^{*} \mathrm{ku}^{\mathrm{B}}\right)$. See Chen Guoqing, "Wuwei Handai yijian shiwen zai buzheng," 93. The Wuwei editors (15) do not transcribe a character here; cf. Akahori and Yamada (396).

207. Lin 林 is a variant of lin 淋; cf. Wuwei editors (16), Akahori and Yamada (397, n. 240), and Zhang Yanchang $(135$, n. 2). Our reading of lin is drawn from the Suwen; see Zhang Yinan, ed., Huangdi neijing suwen jizhu, juan 8, "Liuyuan zhengji da lun" 六 元正紀大論, 304. The line reads: "The urine is yellow and red; if extreme, then it is a case of lin" (xiaobian huangchi, shen ze lin 小便黃赤, 甚則淋).

208. Qisi yumen zhong 起死玉門中 is a metaphor for some form of erectile dysfunction. It is unclear what $s i$ 死 specifically refers to. Mawangdui (Tianxia zhidao tan 天下 至道談) also contains a reference to death under similar circumstances, but it is unclear whether this refers to a premature erection or the loss of an erection. See Harper, Early Chinese Medical Literature, 425; Qiu, ed., Changsha Mawangdui Hanmu jianbo jicheng, vol. $6,163(3-14)$.

209. With respect to $j u$ 莒, the Wuwei editors (15) doubt this character could be tai 苔. Yamada (396) and Zhang Yanchang $(135, n$. 5), however, write this character as $j u$ 莒, an opinion with which we concur. The meaning of geng er ju qing zhong 更而莒輕重 is unclear; on this point, see Akahori and Yamada (397, n. 242).

210. The Wuwei editors (15) and Akahori and Yamada (396) think that there is one character before jiegeng 桔梗. We have consulted the photographs provided in Wuwei Handai yijian and Hexi jiandu; we have determined that the characters, which are not completely clear, are in fact neishang 內傷 based on the shape of the graphs. Furthermore, Zhang Yanchang (134) states that there should be two characters before jiegeng 桔 
十分, 牛膝、續[迦]、[方] $]^{211}$ 風、遠志、杜仲、赤石脂、山荣舆 $212 、$ 柏實各 四分, 月從容 ${ }^{213}$ 、天雄、署與 $214 、$ 虵 $215 \square$ 。 $\square \square^{216}$ 五物皆并冶 $\square^{217}, \square 85$ B

[Indeterminate number of missing characters ...] One fen of human hair ... [5 illegible characters interspersed with 7 untranslatable characters] ... Pulverize and combine all eight [2 illegible characters], drinking a square inch-spoonful $[2.76 \mathrm{ml}]$ with warm alcohol. Drink three times a day. A formula of Master Lü Gong. In cases where there is pus, one can apply acupuncture to oneself ... [8 illegible characters] ... comes out and there is blood, which will not become pus (?).

A formula to treat [illnesses] submitted by the lords of Donghai and White Waters (?):218 In treating male ailments, there are seven afflictions and seven injuries. What are the seven injuries? The first refers to the privates being cold; the second is impotence; the third refers to decline in the privates; the fourth to moistness and itchiness at the base of the scrotum with yellow juice coming out with extreme pain. The fifth refers to excessive urination; the sixth refers to pain in the penis like lin [i.e., an ailment causing the urine to be yellow-red in color]. The seventh refers to spontaneous ejaculation and the ill living in isolation but nevertheless getting excited. With respect to matters [of the bedroom], there is no erection. During an erection, there is "death" [i.e., lost or premature erection] within the "gates of life" [i.e., the vagina]. Thoughts are constantly

梗, which he renders as zhizhi 治之. While we concur that there should be two characters there, we cannot verify that they are, in fact, zhizhi 治之, because the picture is unclear.

211. Duan 斷 and fang 方 are unclear. But we can discern the shape of these characters.

212. Shanzhuyu 山朱舆 is a variant of shanzhuyu 山茱英.

213. Yuecongrong 月從容 is a variant of roucongrong 肉蓯蓉; see Wuwei editors (16) and Zhang Yanchang (136, n. 9).

214. Shuyu 署與 is a variant of shuyu 薯預; cf. Zhang Yanchang $(135$, n. 10).

215. She 虵 is a variant of she 蛇; cf. Wuwei editors (16). Akahori and Yamada (397, n. 252) and Zhang Yanchang (135, n. 11) believe this means shechuangzi 蛇床子 (Cnidium or Cnidium monnieri).

216. The Wuwei editors (15) tentatively identify these two graphs as fan shi 凡十; cf. Akahori and Yamada (397) and Zhang Yanchang (134). But the graphs are too blurred for us to be confident in this identification.

217. The Wuwei editors (15) tentatively identify this graph as he 合; cf. Akahori and Yamada (397) and Zhang Yanchang (134). But the graphs are too blurred for a confident identification.

218. The punctuation of this line is uncertain. One reviewer suggested punctuating the line differently, removing the break between Donghai 東海 and Baishui 白水. The line would thus read, "the Lord of White Waters in Donghai." It is difficult to adjudicate between these two readings. Baishui was a toponym, one that referred to multiple locations in Han China (in Guanghan 廣漢 and Nanyang 南陽). None of these locations, however, can be pinpointed to Donghai commandery, though this may simply reflect the limitations of our knowledge of ancient geography. 
directed at obtaining women, which increase by day [5 untranslatable characters] ... Sometimes, there is pain in the abdomen; below there is urine leaking from the bladder. This illness is called "internal injury." [2 illegible characters ...]

Balloon flower, 10 fen.

4 fen each of Achyranthes; Japanese teasel; Fangfeng; Chinese senega [Polygala sibirica or P. tenuifolia]; Eucommia [Eucommia ulmoides]; Halloysite; Asiatic cornelian cherry [Cornus officinalis]; and Arbor-vitae [Thuja orientalis or Biota orientalis].

As for Mongolian Broomrape [Cistanche salsa or C. desertica]; Chinese or Szechuan aconite; yam [Dioscorea opposita];219 Cnidium [Cnidium monnieri] ... [Indeterminate number of missing characters and 2 illegible characters] ... all five of the substances, pulverize [ 1 illegible character and an indeterminate number of missing characters] ...

\section{Tablets 86A-86B}

$\square \square \square^{220}$ 大風221方 : 雄黃、丹沙、譽石、 $\square$ 茲石、玄石 ${ }^{222}$ 、消石 $\square$ 長 $\square$ 一兩，人參 $\square\left[\right.$ f搗 $^{223}$ 之各異質 $224 \square$ 三重盛藥 $\square \square$ 三石 $\square \square[\text { 下] }]^{225}$ 三日 $86 \mathrm{~A}$ $\square$ 熱 $\square$ 上 $\square \square+\square \square \square$ 飯藥以 $\square$ 豬月、魚、辛，井日知，六十日愈。 $\square$ 皆路 ${ }^{226}$, 隨皆復生。 $\square$ 雖折 ${ }^{227}$, 能復起, 不仁皆仁。86B

219. Our translation draws from Barrett (372).

220. The Wuwei editors (16) transcribe the two characters we have marked blank as e bing 恵 (惡) 病 (see n. 138 above). These two characters are illegible in the photographs of the strips.

221. Dafeng 大風 refers to mafengbing 麻風病 (leprosy); see Wuwei (16) and Zhang Yanchang $(135$, n. 1).

222. What zishi 兹石 and xuanshi 玄石 refer to is unclear; see Akahori and Yamada

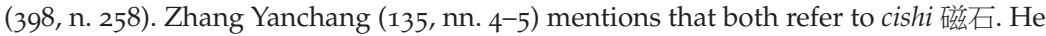
thinks there must be a mistake, because one would not expect to find the same substance mentioned twice in a row in a single formula.

223. The graph is not entirely clear, but we have determined based on the form of the character that it is dao 搗; the Wuwei editors (16) also tentatively came to similar conclusions; cf. Akahori and Yamada (398) and Zhang Yanchang (135).

224. Some disagreement exists as to how to transcribe this character 㯕. The Wuwei editors (16) and Zhang Yanchang $(135$, n. 6) regard this as si 斯. Akahori and Yamada $(399$, n. 259) however disagree.

225. The Wuwei editors (16) do not transcribe the xia 下; cf. Akahori and Yamada (398) and Zhang Yanchang (135). The photograph of the graph is admittedly blurred. We however have determined that the graph is xia 下 based on its shape.

226. $L u$ 蕗 is a variant of luo 落; cf. Wuwei (16), Akahori and Yamada (398, n. 260), and Zhang Yanchang (136, n. 3).

227. Akahori and Yamada (399, n. 261) treat zhe 折 as a graphic variant of shi 逝. However, we disagree, since the line makes sense as it is currently written. 
Indeterminate number of missing characters and 2 illegible characters].

A formula for leprosy.

Realgar or Red arsenic sulphide; Cinnabar; Arsenolite; 228 [indeterminate number of missing characters]; Cishi (?); Xuanshi, Epsom Salts; [indeterminate number of missing characters] ... long ... [indeterminate number of missing characters], one liang [13.8 g]. Ginseng ... [indeterminate number of missing characters] ... beat each of these separately ... [an indeterminate number of missing characters, many illegible characters, as well as many untranslatable characters on $86 \mathrm{~A}$ and $86 \mathrm{~B}] \ldots$

pork, fish, and spicy [vegetables]. In 30 days, they will improve; in 60 days his or her condition will be cured. [Indeterminate number of missing characters];

Although the [hair] has fallen out, it will grow back again ... [Indeterminate number of missing characters] ... Although a person has broken [a limb], he or she will be able to recover, and although the person is numb, he or she will be able to feel again.

\section{Tablets 87A-87B}

治加229及久創230及馬䆩方：取陳231駱蘇232一升, 付子廿枚, 蜀椒一升, 乾當歸二兩, 皆父且之。以駱蘇煎之, 三沸, 藥取以傅之, 良甚。治人 卒233雍方 : 冶赤石脂, 以寒水和, $87 \mathrm{~A}$

228. For this translation, see Sivin (294).

229. Jia 加 is a graphic variant of jia 痂; cf. Wuwei editors (17), Akahori and Yamada (399, n. 263), and Zhang Yanchang (136, n. 1).

230. According to the Wuwei editors (17), Akahori and Yamada (399, n. 264), and Zhang Yanchang $(137, \mathrm{n} .2)$, jiuchuang 久創 is a variant of jiuchuang 炎瘡. While we concur with them about the second character (see above), we do not feel that the first character needs to be substituted. The line makes sense as is.

231. He Shuangquan (39) transcribes chen 陳, whereas the Wuwei editors (17), Akahori and Yamada (399), and Zhang Yanchang (136) treat this as an illegible character. We checked the photograph and concur with He Shuangquan that the character should be written as chen.

232. Previous scholars have interpreted luosu 駱蘇 as a reference to camel butter. They reason that luo 駱 means camel. They furthermore note that $s u$ 蘇 is a variant of $s u$ 酥; cf. Wuwei editors (17), Akahori and Yamada (399, n. 266), and Zhang Yanchang $(137$, n. 4). We should add that while it is possible to make butter from camel milk, this practice is not attested in the received tradition, quite unlike the milk from other mammals. There is moreover another equally plausible interpretation of luosu: namely, to take luo 駱 (Schuessler $2-1<\mathrm{LH}{ }^{*} \mathrm{lak}$ ) as a variant of lao 酪 (Schuessler $2-1<\mathrm{LH}$ *lak). The compound would thus be laosu (酪蘇, 酪酥), a cheese product attested in received texts from Six Dynasties to Qing.

233. $\mathrm{Zu}$ 卒 is a variant of $c u$ 猝; cf. Wuwei editors (17) and Zhang Yanchang $(137, \mathrm{n} .6)$. 
塗雍上, 以愈為故, 良。・治狗踾人創急方 : 煩 ${ }^{234}$ 狼毒, 冶以傅之。創 乾者, 和以膏傅之。治漡 235 火湅 ${ }^{23} 6$ 方 : 煩 $\square$ 羅, 冶以傅之, 良甚。87 B

A formula to treat scabs, long-term external wounds, and saddle sores (?):

Take aged camel butter (?), one sheng [200 ml].

Szechuan aconite root, 20 pieces (mei).

Szechuan pepper, I sheng [200 ml].

Dried Chinese angelica, 2 liang [27.6 g].

Mince all of these.

Use the camel butter to fry the substances. Bring the mixture to boil three times. Take the medicine out and apply it. Extremely efficacious.

A formula to treat a person with violent abscesses that erupt suddenly. Pulverize Halloysite with cold water to mix. Spread on the abscess until cured. Efficacious. A formula to treat a dog-bite wound that is painful: roast Chinese Wolfsbane [Euphorbia fischeriana], pulverizing and applying it to the wound. If the wound is dry, mix [the medicine] with paste to apply it. ${ }^{237}$ A formula to treat burns from hot water, fire, and metal: roast [ 1 illegible character and 1 untranslatable character]. Pulverize and apply it. Extremely efficacious.

234. Fan 煩 (Schuessler 24-51 < LH *buan) is a phonetic loan for fan 燔 (Schuessler 24-51 < LH *buan). Here, we are following Akahori and Yamada (400, n. 270); for a different view, see Wuwei (17) and Zhang Yanchang (137, n. 8), as they gloss fan to mean daosui 搗碎 (to break into pieces). However, we could not find any evidence for this reading.

235. Shang 漡 is a variant of tang 湯; cf. Wuwei editors (17), Akahori and Yamada (400, n. 272), and Zhang Yanchang (137, n. 9).

236. Lian 湅 is a variant of lian 煉. The phrase tanghuolian 湯火湅 is difficult to understand. The Wuwei editors (17) take this as a reference to a burn from hot water. Akahori and Yamada (400, n. 272) understand this as a burn produced through hot water or fire. We, however, read this as a burn produced through hot water, fire, or hot metals (this reflects the fact that the character on the strip is a variant for the verb to smelt iron).

237. Here, our reading follows from the punctuation proposed by Akahori and Yamada (399), and Zhang Yanchang (136). This is not the only possible reading of the line. An alternative proposed by a reviewer reads as follows: 冶以傅之創。乾者, 和以膏 傅之 ("pulverize and spread the medicine over the wound. If the medicine dries out, mix with paste to apply it"). The practice of mixing paste to medicine for reuse is attested in the Mawangdui corpus. For an example (which is worded differently), see Qiu ed., Changsha Mawangdui Hanmu jianbo jicheng, "Wushier bingfang," 271 (319-09); Harper, Early Chinese Medical Literature, 281. While plausible, we prefer the other punctuation because it supplies an explicit subject (chuang 創 or wound) for the second sentence. 


\section{Tablets 88A-88B}

治邚人膏藥方 : [樓] ${ }^{23} 8$ 三升, 當歸十分, 白茝四分, 付子冊枚, 甘草七 分, 弓大隽 239 十分, 菒草 240 二束, 凡七物以朌膊 ${ }^{241}{ }^{\text {高 }}{ }^{242}$, 舍之。 $88 \mathrm{~A}$

治邚人高藥方 : [樓] 243 三升, 甘草七分, 付子世枚, 菒草二束, 弓大隽十 枚, 白茝四分, 當歸十分, 凡七物以朌膊高之。之之 $\square$, 凡六物合後 曰88B

\section{A formula for a medicinal paste to treat women:}

[Unknown quantity], 3 sheng [6oo ml].

Chinese Angelica, 10 fen.

Fragrant Angelica, 4 fen.

Szechuan aconite root, 30 pieces (mei).

Licorice, 7 fen.

[3 untranslatable characters, including 1 non-standard graph], 10 fen.

Chinese lovage [Ligusticum sinense or L. jeholense], 2 bundles.

All seven of these substances should be paired with pig fat to make a paste. Place it.

238. We were unable to make out the character preceding sansheng 三升, which the Wuwei editors (17) and Zhang Yanchang $(137$, n. 2) transcribe as lou 樓 (and which they treat as short for gualou 栝樓 or Trichosanthes [Trichosanthes kirilowii]. This is based on the duplicated text below, where the character is clearer, so we include the graph in brackets here. Still, we do not have enough context to make a firm identification of the pharmacological substance.

239. The meaning of the three characters gongda- $X$ 弓大隽 is unknown; see Wuwei (17), Akahori and Yamada (401, n. 273), and Zhang Yanchang (137, n. 3).

240. Gaocao 菒草 is a variant of gaoben 葈本; cf. Wuwei editors (17), Akahori and Yamada (401, n. 274), and Zhang Yanchang (137, n. 5).

241. With respect to fenbo 朌膊, Zhang Lijun 張麗君 takes the fen 朌 as a phonetic loan for fang 肪. Zhang also argues that $b o$ 膊 refers to minced or sliced meat. As such, fangbo 肪膊 means pig fat (zhurou zhifang 豬肉脂肪), which makes sense since the substance was used in the formula to make a spreadable paste. See Zhang Lijun 張麗君，

“Fenbo kaoshi” 朌膊考釋, Gu Hanyu yanjiu 古漢語研究 1995.1: 65.

While we agree with Zhang's interpretation because of the larger context of the formula, we disagree with her reasoning. According to Baxter, fen 朌 (Schuessler 33-30 $<\mathrm{LH}$ *pan) and fang 肪 (Baxter < LH *buay) were not phonetic loans for each other. Consequently, we believe that the scribe probably mistook fen 朌 for fang 肪, due to graphic similarity.

242. Gao 高 is probably an error for gao 高; see Wuwei (17), Akahori and Yamada (401), and Zhang Yanchang (138, n. 7).

243. The Wuwei editors (17) transcribe this character as lou 樓. While the graph is not entirely clear, we have transcribed it in this way due to the shape of the character. 
A formula for a medicinal paste to treat women:

[Unknown quantity], 3 sheng [600 ml].

Licorice, 7 fen.

Szechuan aconite root, 30 pieces (mei).

Chinese lovage, 2 bundles.

[3 untranslatable characters, including one non-standard graph], 10 pieces (mei).

Fragrant Angelica, 4 fen.

Chinese Angelica, 10 fen.

All seven of these substances should be paired with pig fat to make a paste. [8 untranslatable characters and 1 illegible character] $]^{244}$

\section{Tablets 89A-89B}

百病膏藥方：蜀椒四升，白茝一升，弓窮一升，付子世果，凡四物父 且, 漬以淳溘三升, 漬 $\square \square \square$ 三厅, 先 $\square \square \square \square$ 89A

枚，煎藥 $\square \square \square \square \square \square$ 浚去宰 89B

A formula for medicinal paste for the many illnesses:

Szechuan pepper, 4 sheng [80o $\mathrm{ml}]$.

Fragrant Angelica, I sheng [200 ml].

Szechuan lovage, I sheng [200 ml].

Szechuan aconite root, 30 heads $(k e)$.

Mince and soak all four of these substances with 3 sheng [6oo ml] of pure, strong vinegar; strain [3 illegible characters] ... 3 jin [66o g]; first (?) [4 illegible characters] ... pieces ( $m e i)$; decoct the medicine [6 illegible characters], straining and getting rid of the sediment ...

\section{Tablets 90A-90B}

五辰、辛不可始久判, 飲藥必死。甲寅、乙卯不可久判, 不出旬, 死。 五辰不可飲藥，病者日益加 $\square^{245} 90 \mathrm{~A}$

244. We are puzzled by the final text (zhizhi ... hou yue 之之 ... 後曰). The Wuwei editors (17) and Zhang Yanchang $(138, n .8)$ speculate that this portion of the text bears no relation to the formula that precedes it. Akahori and Yamada (400) transcribe the final character as $r i$ 日.

245. We could not make out the last character (after jia 加) on 9oA from the photographs, even though the Wuwei editors (18), Akahori and Yamada (401), and Zhang Yanchang (138) all transcribe it as shen 深. 


\section{無 $\square$ 禁。朔、晦日、甲午，皆不可始久 $\square \square \square \square$ 人月246六日、十六日、 十八日、廿二日，皆不可久可久 ${ }^{247}$ 判見血，止 ${ }^{248}$ 己 $\square \mathbf{9 0 B}$}

On the five chen and xin days, one cannot begin to cauterize or needle; if one drinks medicine, one will certainly die. On jiayin and yimao days, one cannot cauterize or needle, otherwise one will die within the next 10 days. On the five chen days, one cannot drink medicine, otherwise the illness will become increasingly [ 1 illegible character] ... each day. Without [ 1 illegible character]; is proscribed. On new moons and dark nights, as well as on jia and wu days, one cannot start to cauterize ... [4 illegible characters]. On the sixth, sixteenth, eighteenth, and twenty-second days of each month, one cannot cauterize or needle. If one sees blood, one must desist. [ 1 illegible character.]

\section{Tablets 91A-91B}

牛膝半斤, 直 ${ }^{249}$ 五十; 卑 $\square^{250}$ 半斤, 直 $\square$ 五; 朱卧 ${ }^{251}$ 二升半, 廿五; 方 風半斤, 百; 慈石 ${ }^{252}$ 一斤半, 百井; 席虫半斤, 廿五; 小椒一升半, 五 十 ; 山朱㕩二升半, 直五十 ; 黃芩一斤, 直七十 $91 \mathrm{~A}$

黃連半斤, 直百 ; $\square \square$ 二斤, 直廿七, 子威取 ; 河聂半斤, 直七十五; 續斷一斤, 百, 子威取 ; $\square \square \square$ 取藥, 凡直九百廿七 91B

246. The Wuwei editors (18), Akahori and Yamada (401), and Zhang Yanchang (138) omit jiu 久 after shi 始. They also omit ren 人 before yue 月. However, the character for jiu is clear from the photographs. The Wuwei editors (18) and Zhang Yanchang (138) disagree about how many illegible characters follow shi jiu 始久 on 9oB, but we count four. Akahori and Yamada (400) add six illegible characters, omitting both jiu 久 and ren 人.

Renyue 人月 should be interpreted as ruyue 入月 (each month). The phrase occurs in the Qianjin yifang $(28 / 834)$.

247. Kejiu 可久 appears twice in a row on this strip, and the second occurrence is most likely redundant.

248. The Wuwei editors (18) put zhi 止 in brackets, suggesting their uncertainty about this graph. We have confirmed from the photographs that this character is in fact correct.

249. Zhi 直 is a graphic variant of $z h i$ 值; cf. Akahori and Yamada (402, n. 279) and Zhang Yanchang (139, n. 1).

250. Bei 卑 is followed by a character that is partially unclear. Our inspection of the photograph suggests that it is xiao 肖, which means sangpiaoxiao 桑螵蛸 (see above). The Wuwei editors (19), Akahori and Yamada (402), and Zhang Yanchang (139) believe the worth of sangpiaoxiao 桑螵蛸 is twenty-five (nianwu 廿五); however, we cannot verify the character nian $廿$ from the photograph. Also, the totals given (927) do not add up if the missing character is just nian (meaning 20) as it would be 100 short.

251. Zhuyu 朱與 is a variant of shanzhuyu 山茱英 or zhuyu 茱莫; see Akahori and Yamada (402, n. 281).

252. We read these characters as cishi 磁石. But Zhang Yanchang $(139, n .4)$ proposes that shi 石 (Schuessler 2-17< LH *dźak) is a phonetic loan for shi 實 (Schuessler 29-18 $<\mathrm{LH}$ *źit [or dźit?]). According to Baxter (Personal Correspondence), Zhang's reading is implausible on phonological grounds. Zhang furthermore substitutes $c i$ 慈 for $c i$ 磁, which is plausible, as the two characters were probably variants of each other. 
Achyranthes, half a jin [110 g], worth 50.

[ 1 illegible character, probably, "praying Mantis egg case on mulberry branch"], half a jin [110 g], worth [1 illegible character, i.e., probably 125].

Asiatic Cornelian Cherry [Cornus officinalis], 21/2 sheng [500 ml], worth 25.

Fangfeng, $1 / 2$ jin [110 g], worth 100.

Magnetite, $1 \frac{1}{2}$ jin $[330 \mathrm{~g}$ ], worth 130.

Xichong, $2531 \frac{1}{2}$ jin [110 g], worth 25.

xiaojiao, ${ }^{254} 1_{1}^{1} \frac{2}{2}$ sheng [300 ml], worth 50.

Asiatic Cornelian Cherry, 21/2 sheng [500 ml], worth 50.

Baical skullcap, 1 jin [220 g], worth 70.

Golden thread, $1 / 2$ jin [110 g], worth 100.

[2 illegible characters], 2 jin [440 g], worth 27.

Taken from Ziwei.

Hezhou, 255 one-half jin [110 g], worth 75 .

Japanese teasel, 1 jin [220 g], worth 100.

Taken from Ziwei ... [3 illegible characters] ... Medicine procured was worth 927 .

Tablets 92A-B: no medical content, so we have left them untranslated.

253. The meaning of xichong 席蟲 is unclear. Akahori and Yamada $(402, n .282)$ and Zhang Yanchang $(139, n .5)$ treat this as the same as zhezhong 䗪蟲 (Wingless cockroach or Eupolyphaga), discussed above. We are uncertain about conflating the two, since neither Akahori-Yamada nor Zhang provide a reason for this interpretation.

254. The meaning of xiaojiao 小椒, probably some kind of pepper, is unclear to Akahori and Yamada (402, n. 283).

255. The meaning of hezou 河聂 is unclear; see Akahori and Yamada (402, n. 286) and Zhang Yanchang (139, n. 7). 